UDC 681.3.06

SCOPUS CODE 1802

https://doi.org/10.36073/1512-0996-2021-4-46-61

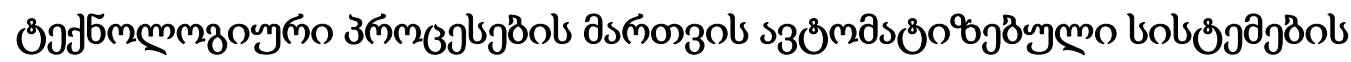

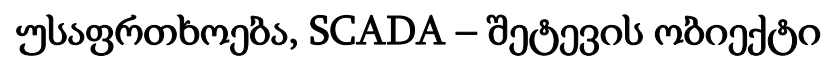

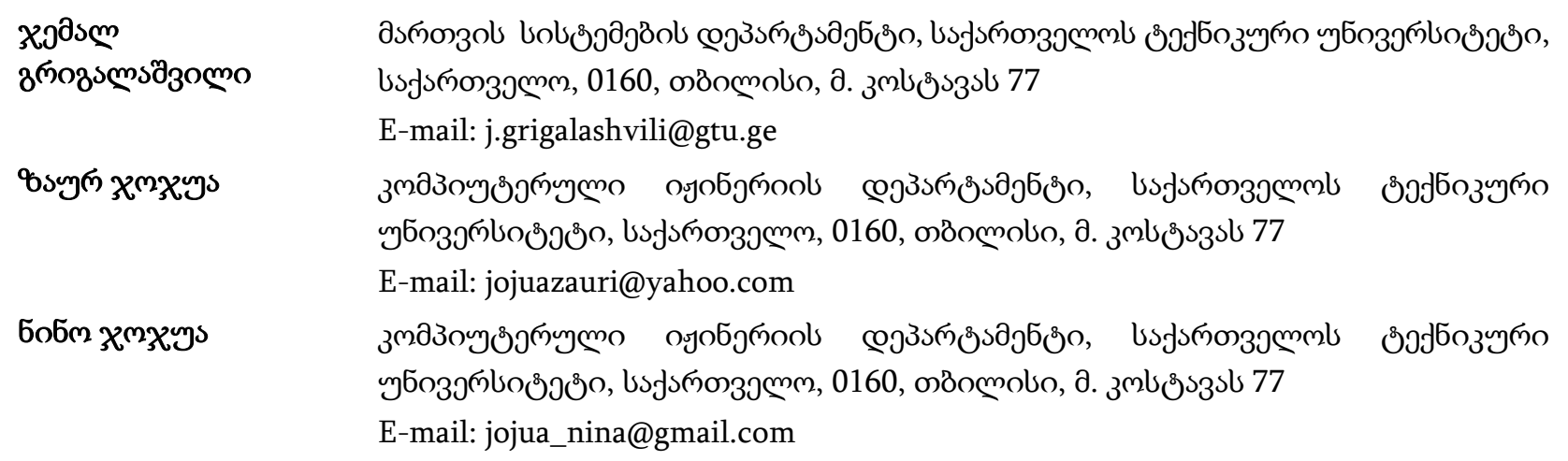

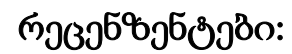

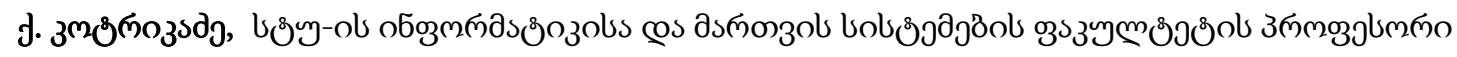

E-mail: ketino27@gmail.com

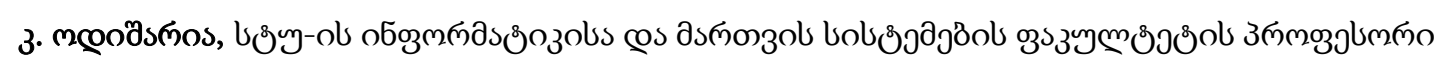

E-mail: o_korneli@yahoo.com

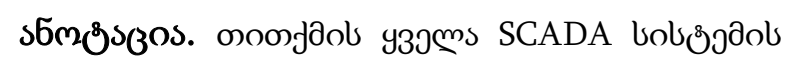

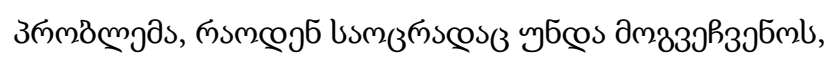

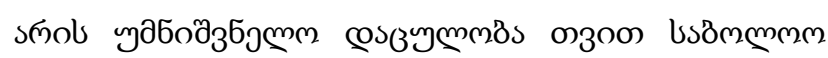

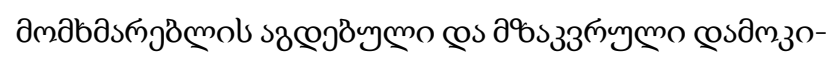

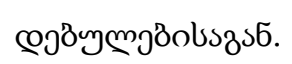

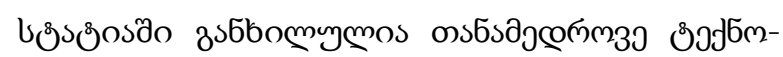

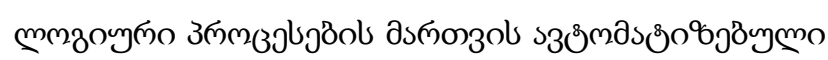

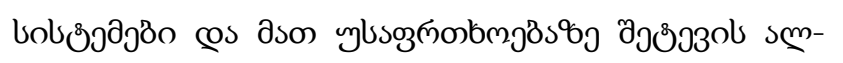

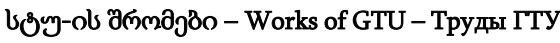
№4 (522), 2021

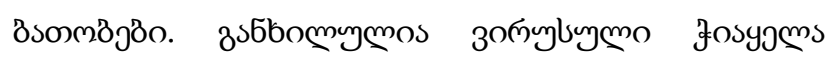

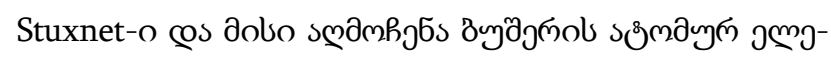

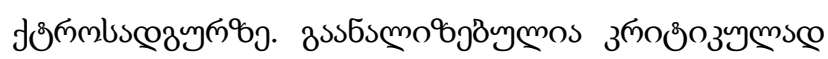

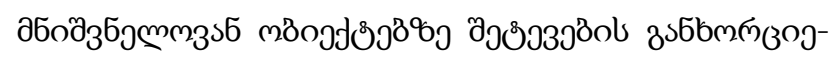

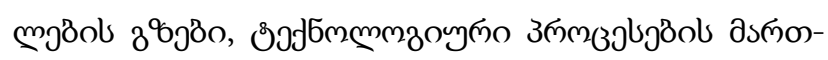

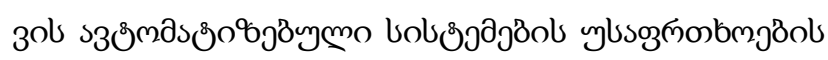

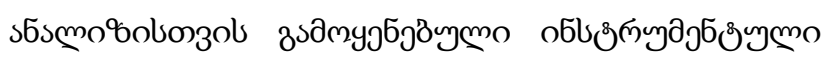

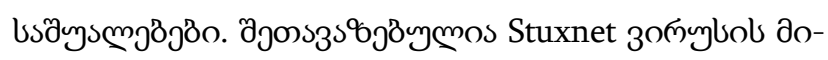

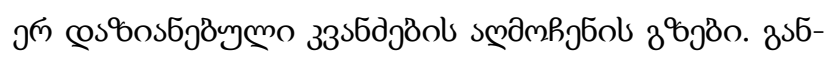

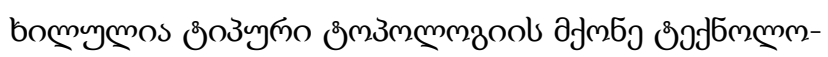




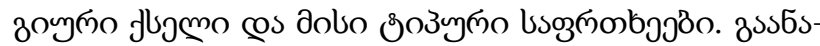

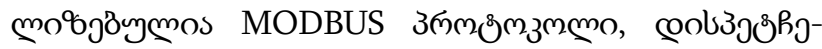

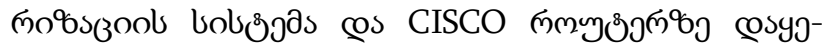

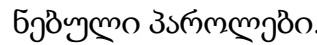

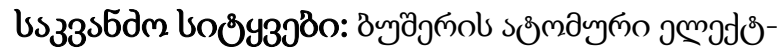

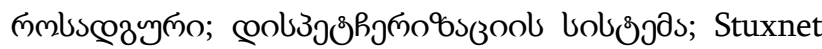

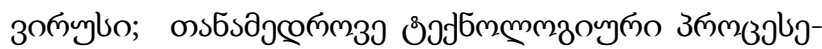

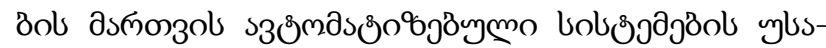

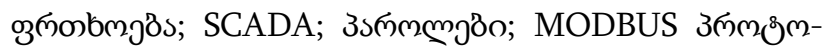

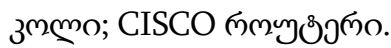

\section{gjuszsmo}

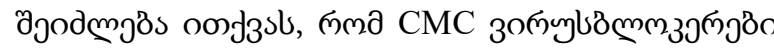

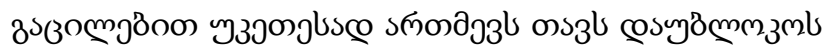

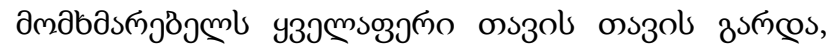

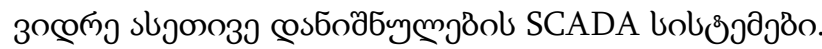

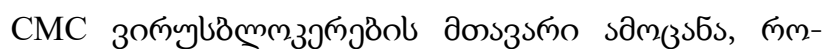

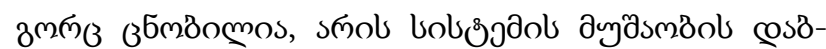

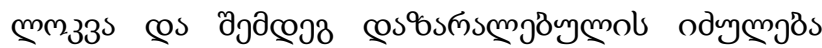

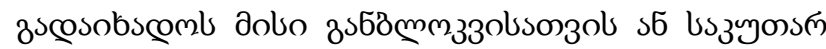

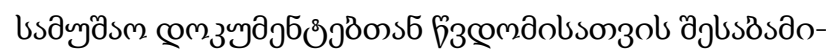

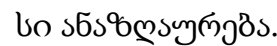

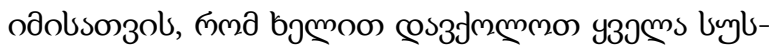

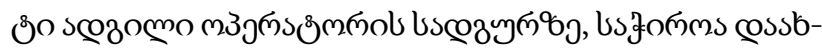

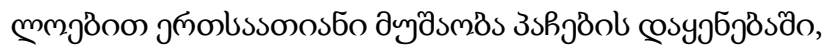

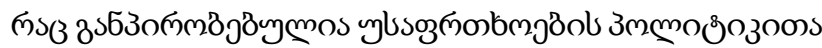

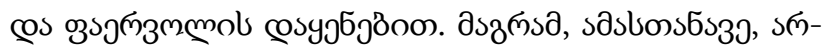

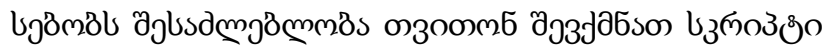

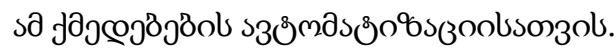

\section{donoossco 6sfomo}

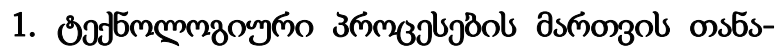

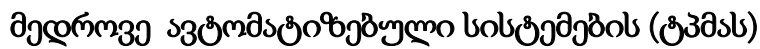

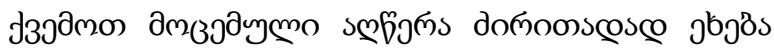

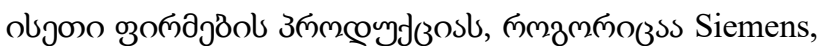

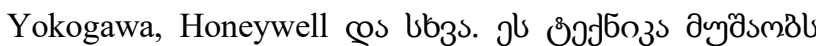

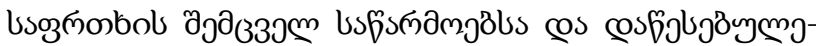

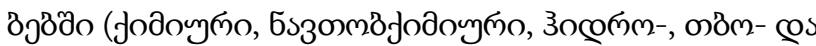

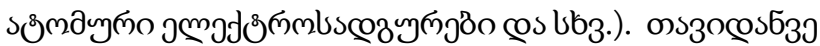

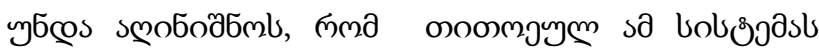

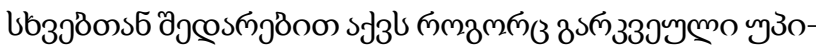

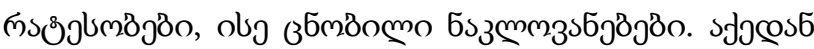

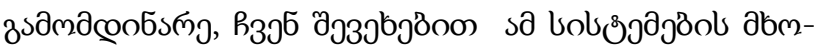

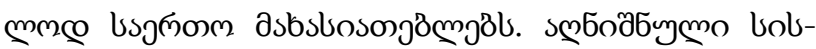

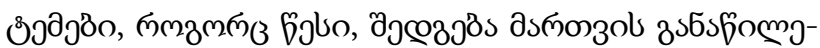

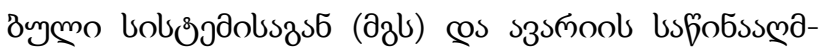

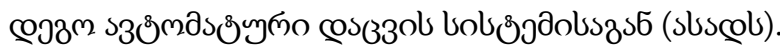

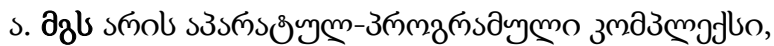

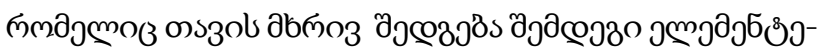
Bolsosst:

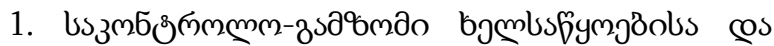

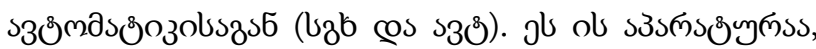

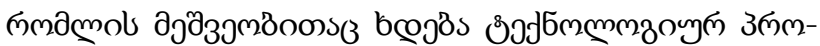

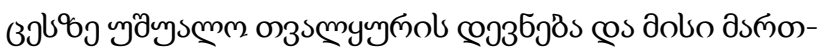
3. умзэмаз

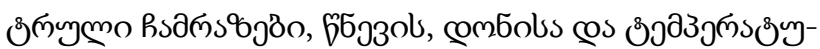

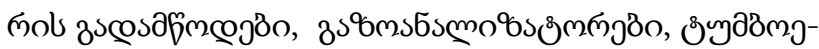

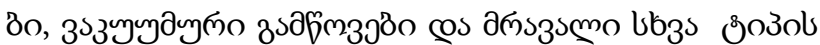

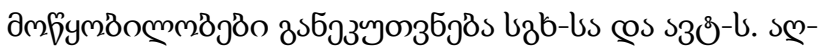

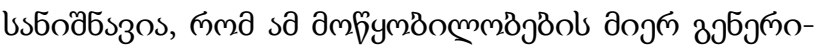

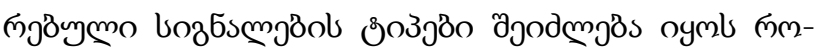




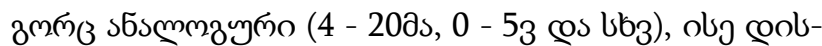
Зॅัว

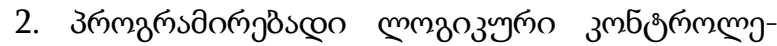

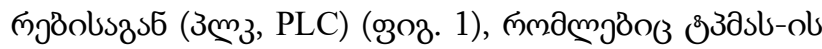

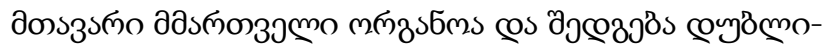

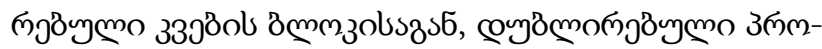
з

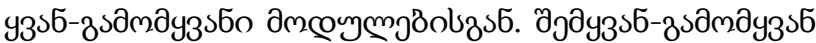

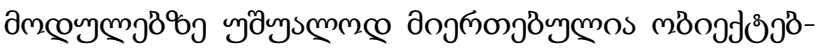

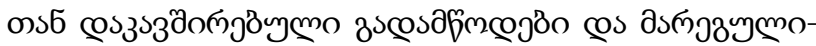

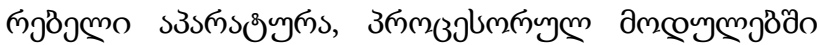

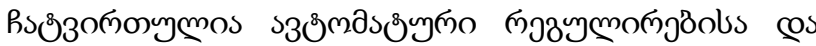

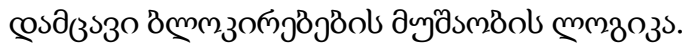

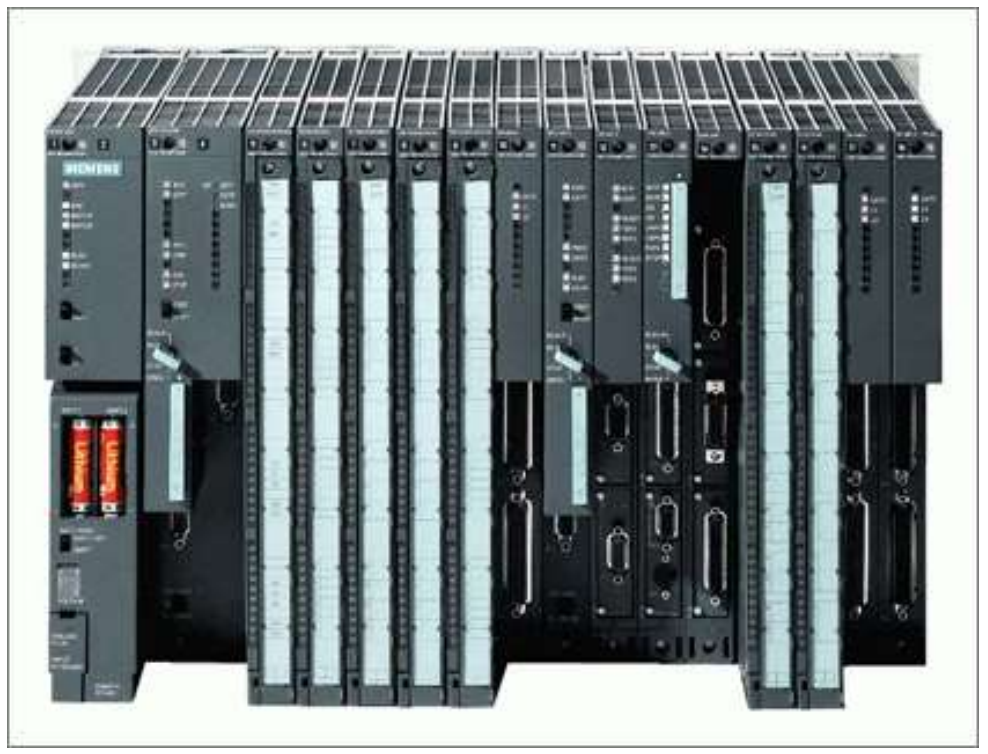

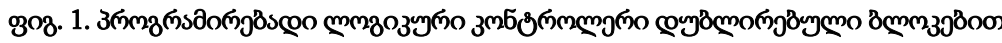
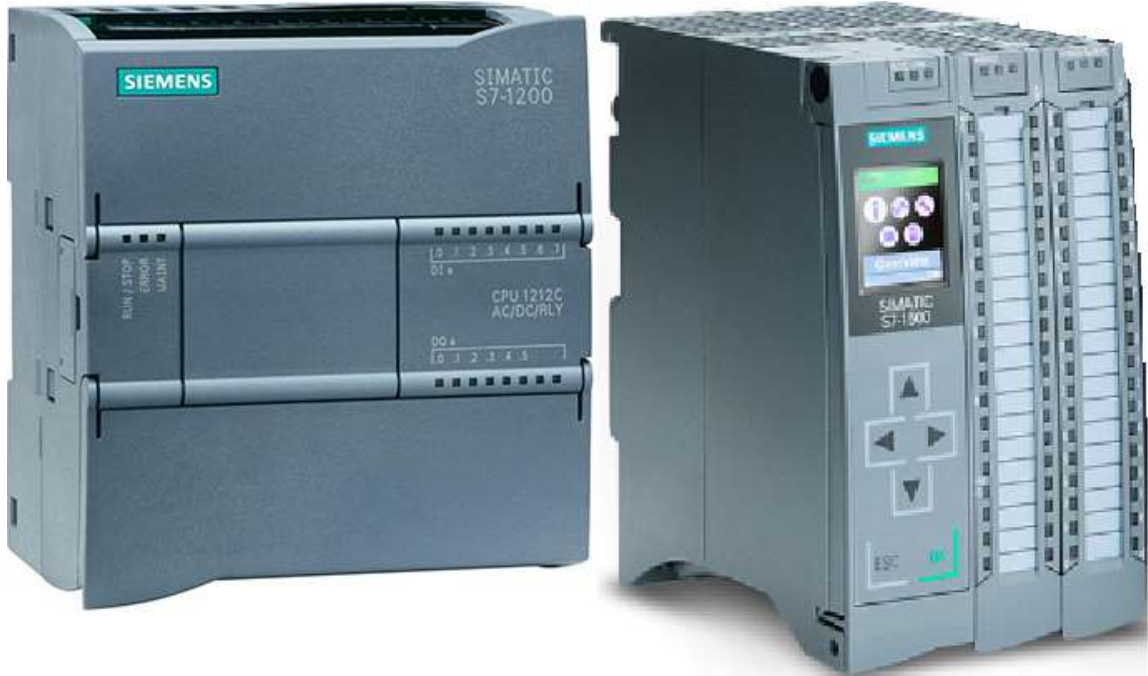

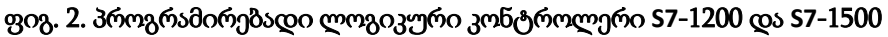

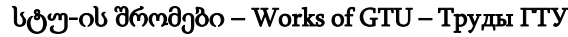




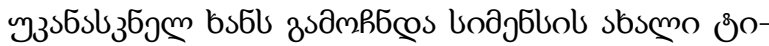

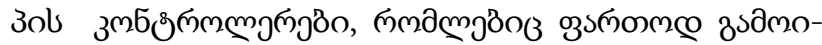

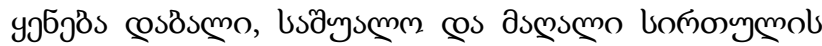

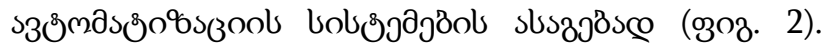

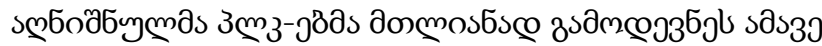

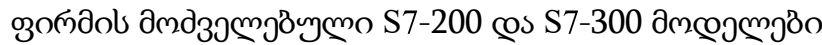

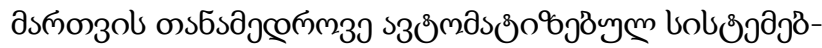

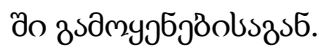

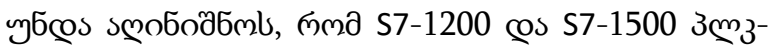

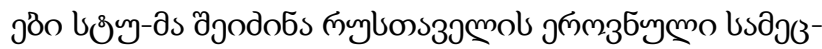

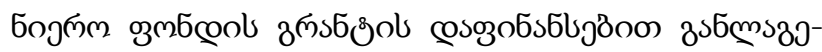

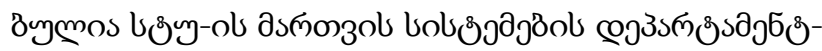

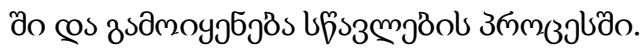

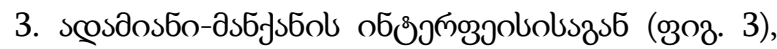

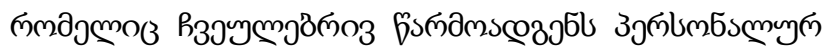

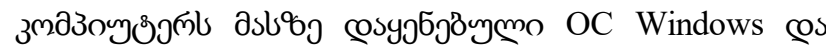

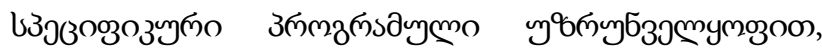

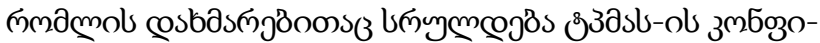

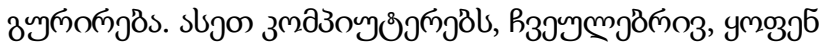

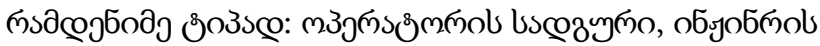

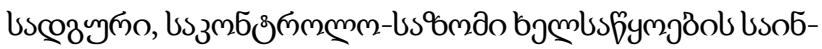

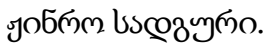

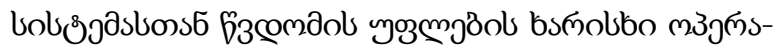

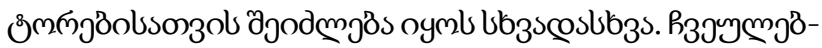

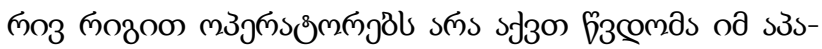

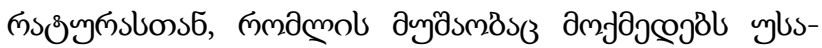

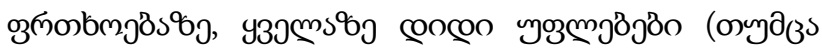

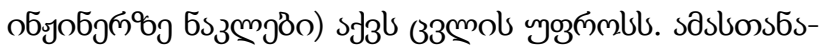

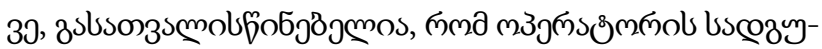

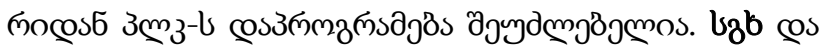

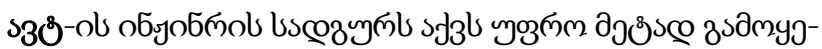

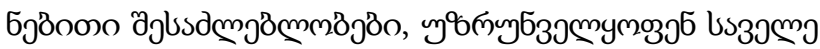

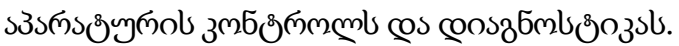

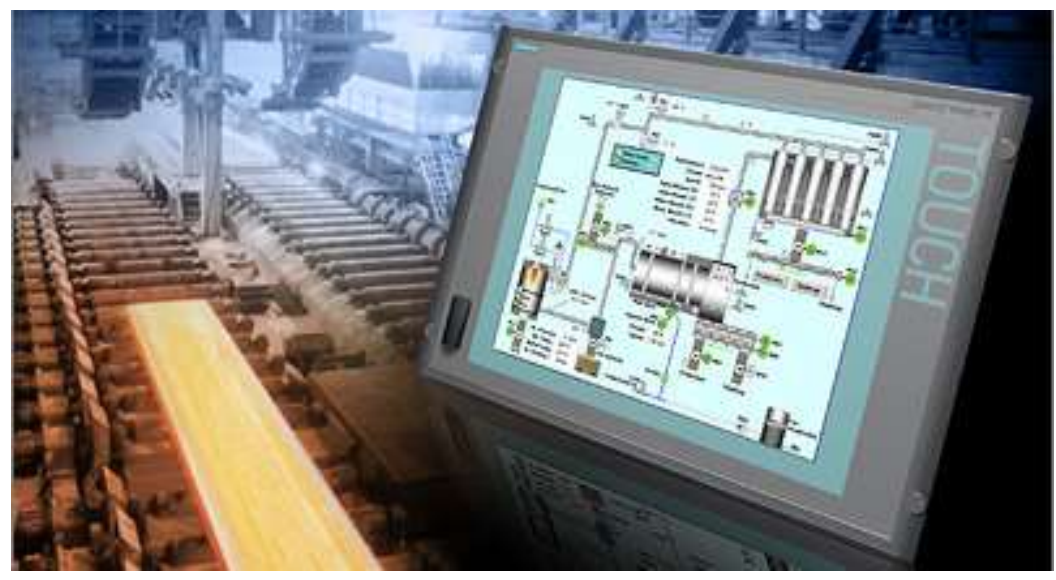

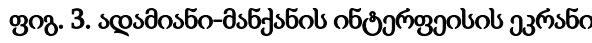

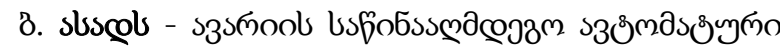

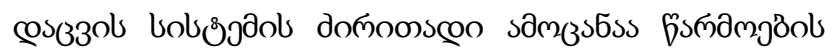

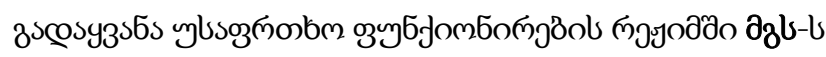

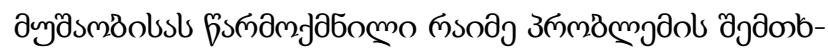

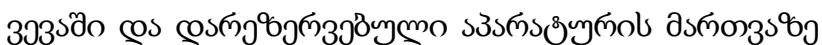
zscoslszms.

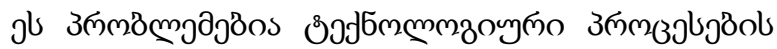

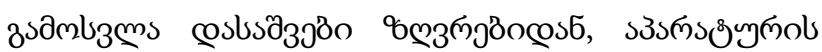




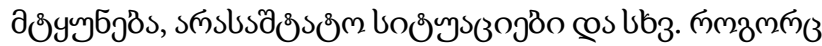

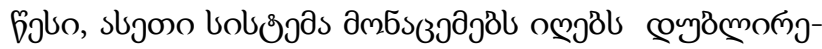

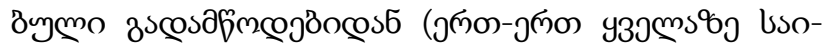

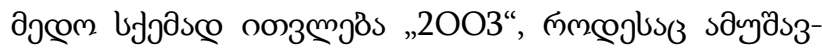

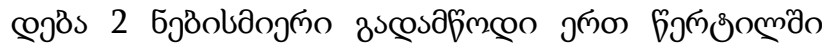

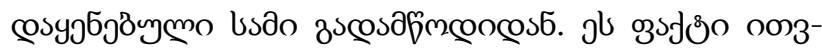

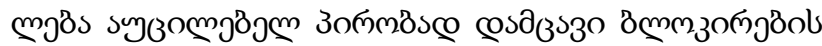

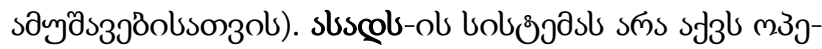

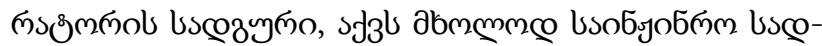

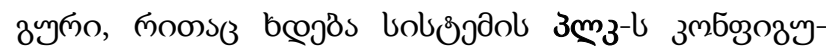

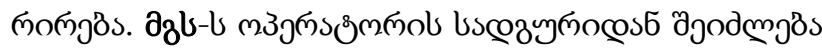

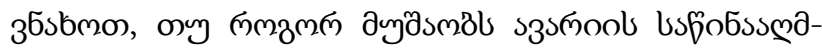

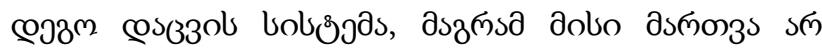
Әучудmos.

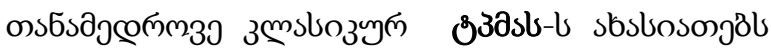

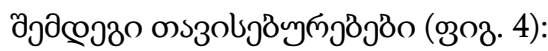

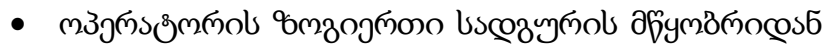

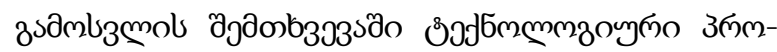

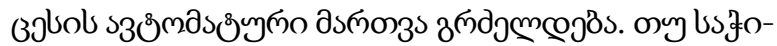

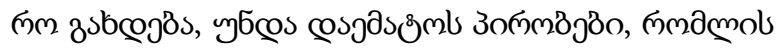

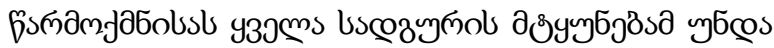

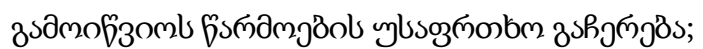

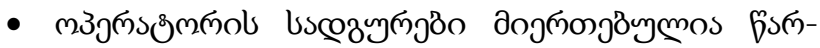

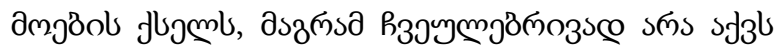

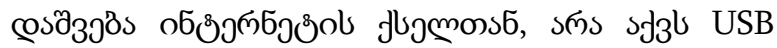

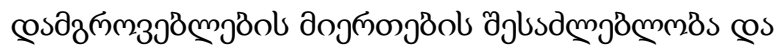

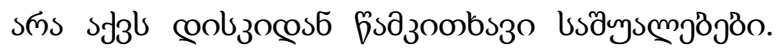

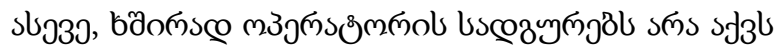

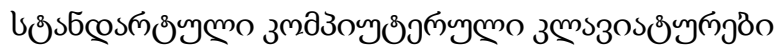

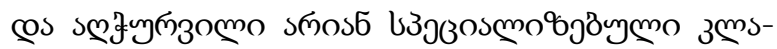

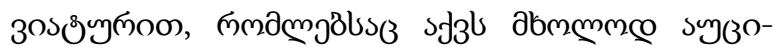

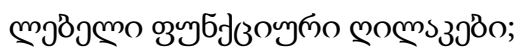

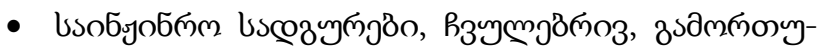

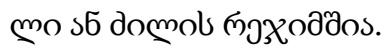

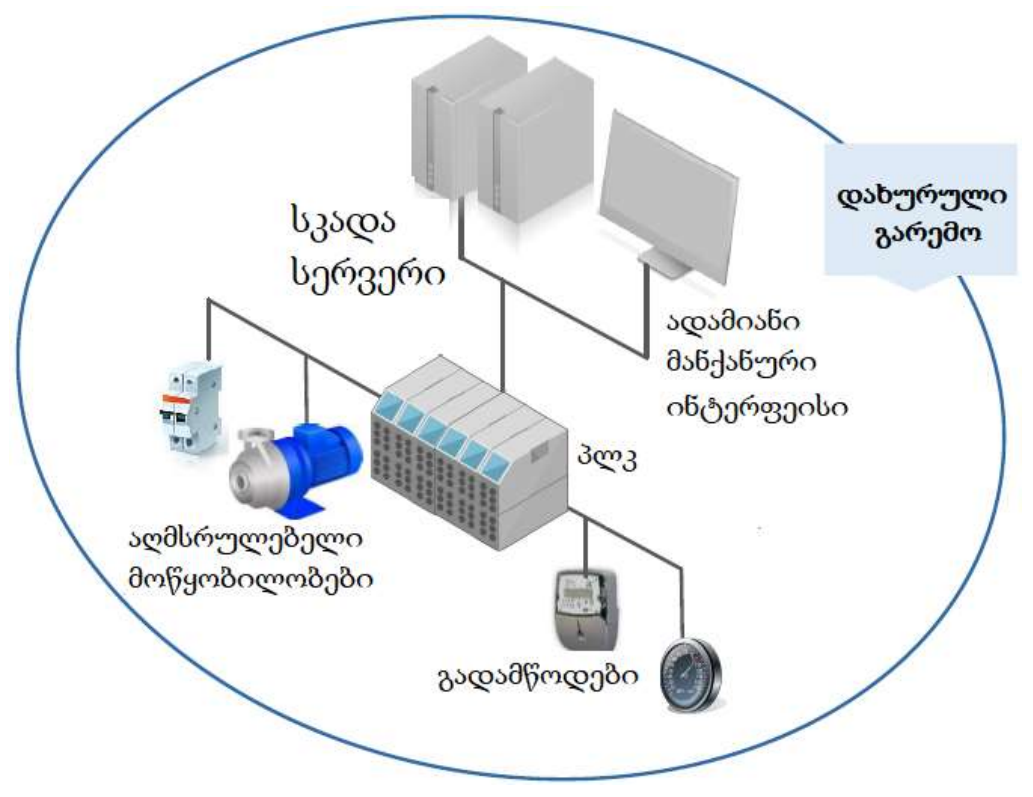

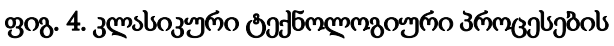

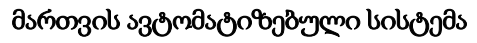




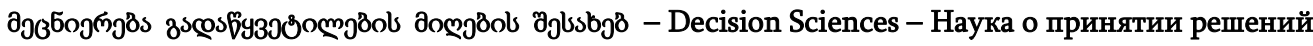

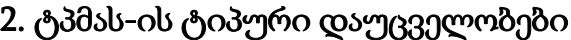

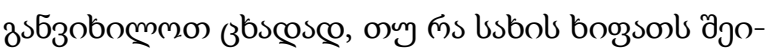

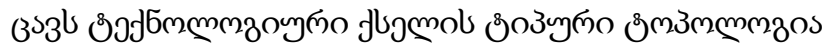
(озов. 5).

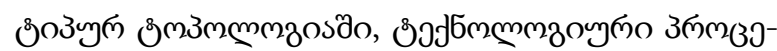

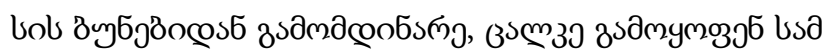

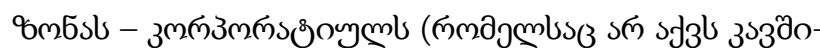

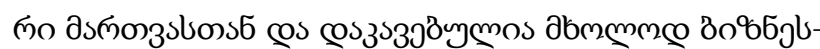

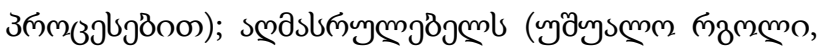

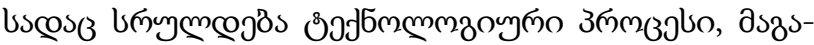

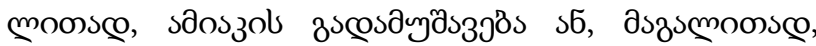

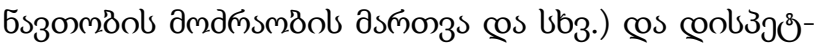

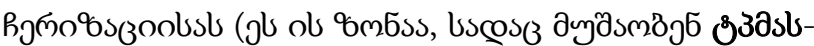

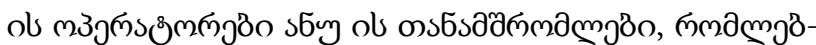

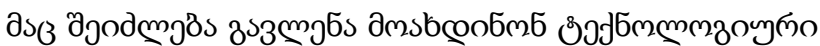

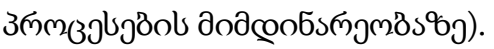

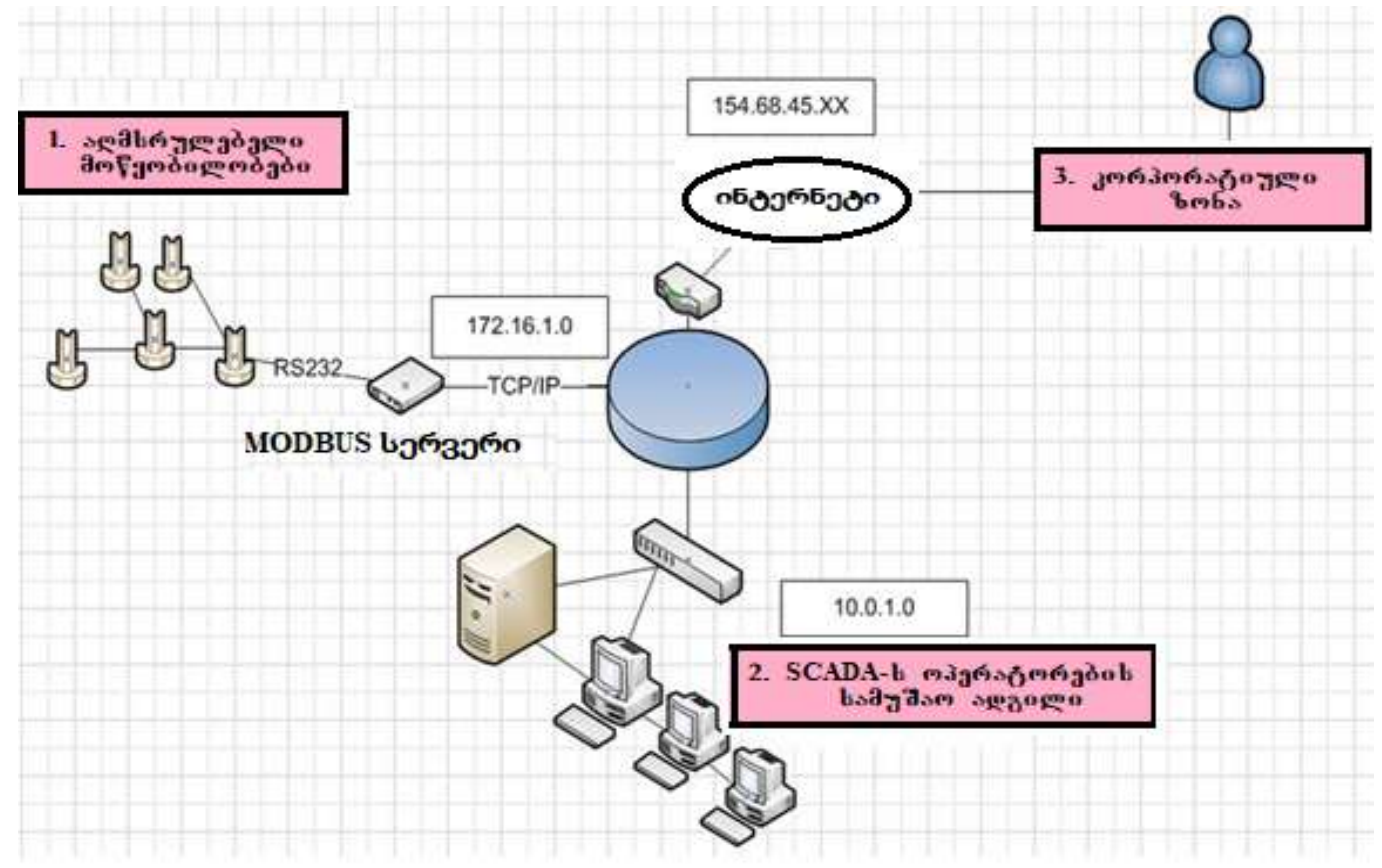

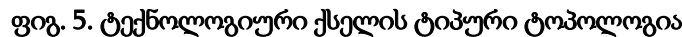

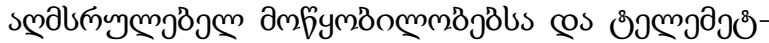

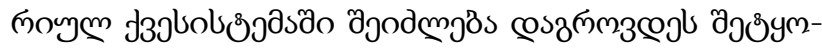

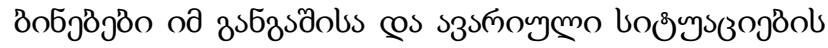

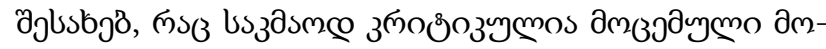

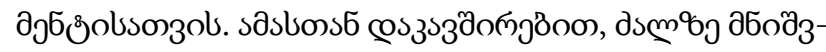

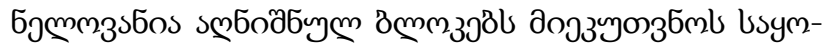

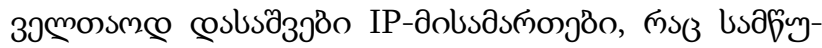

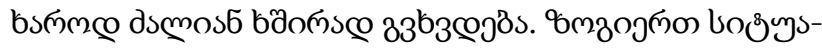

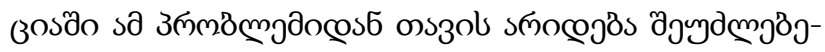

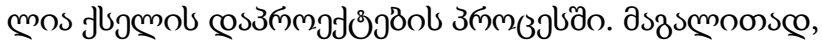

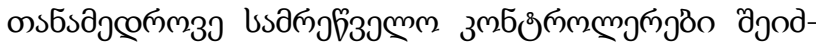

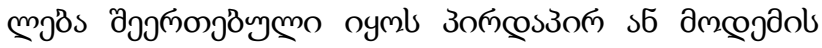

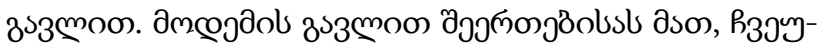

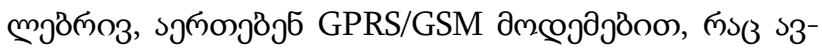

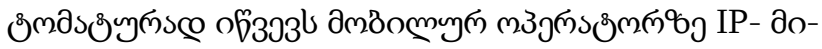

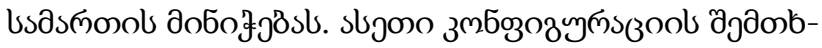

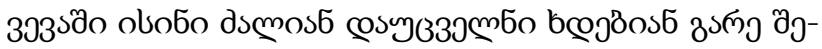

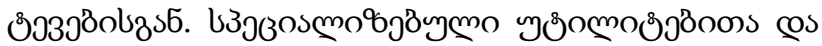




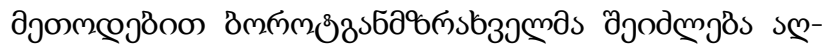

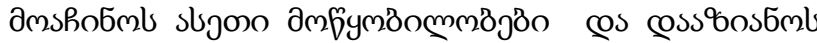

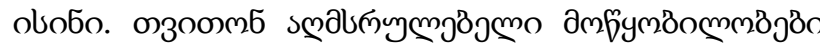

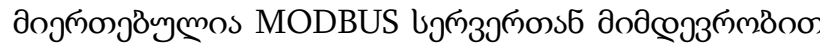

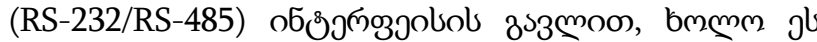

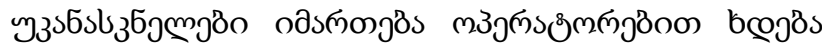

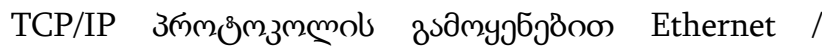
Industrial Ethernet smbols aş3moon.

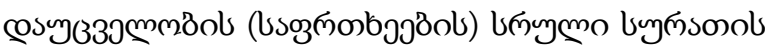

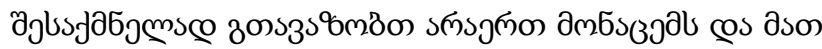

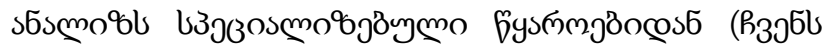

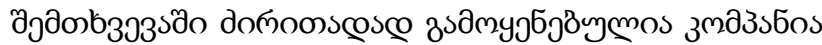

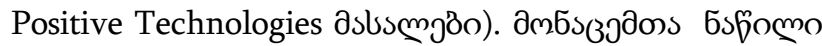

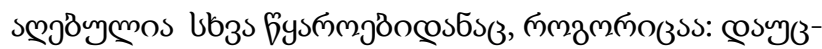

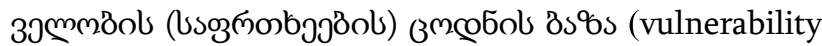

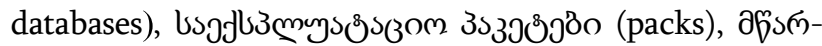

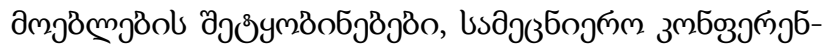

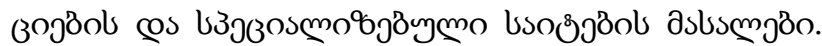

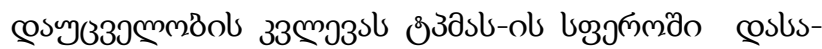

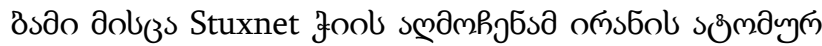

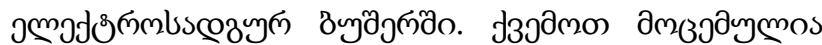

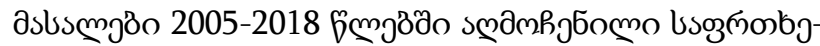

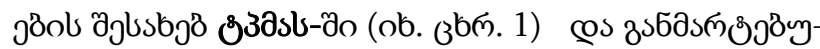

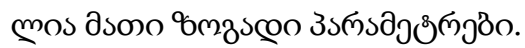

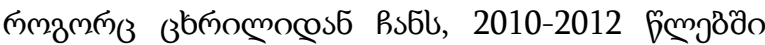

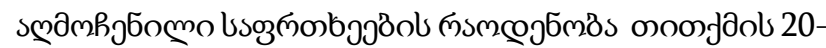

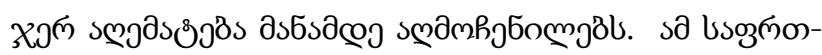

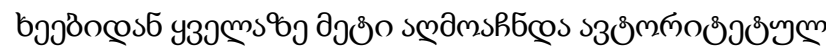

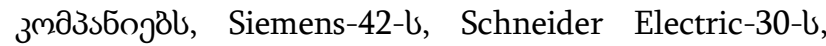
Advantech/Broadwin-22-ls cos General Electric-15-b. jo

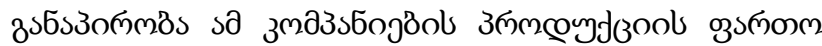

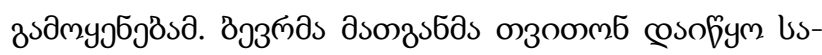

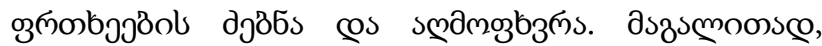

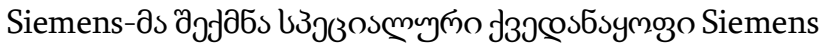
ProductCERT. Computer Emergency Response Team

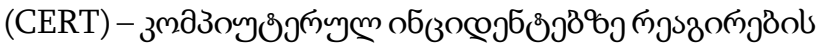

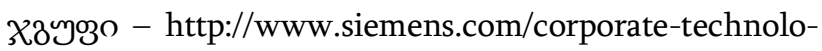
gy/en/research-areas/siemens-cert-securityadvisories.htm.

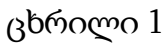

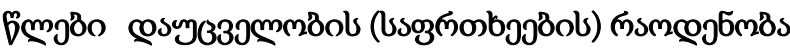

$\begin{array}{ll}2005 & 1 \\ 2007 & 3 \\ 2010 & 11 \\ 2011 & 64 \\ 2012 & 98 \\ 2013 & 158 \\ 2014 & 181 \\ 2012 & 212 \\ 2016 & 115 \\ 2017 & 197 \\ 2018 & 257\end{array}$

2019

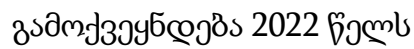

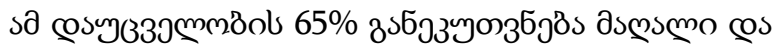

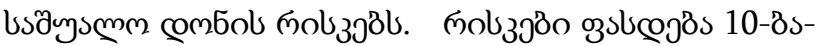

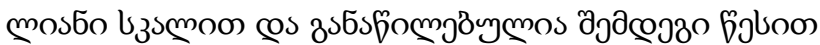
(ob. (3) помпо 2):

उвйомо 2

$0,0<$ CVSS $\leq 3,9-$ cosösmo gombol molzo;

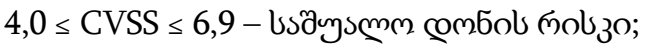

7,0 $\leq$ CVSS $\leq 10,0-$ dsмsме gombol molz

bscos(3, CVSS - Common Vulnerability Scoring System -

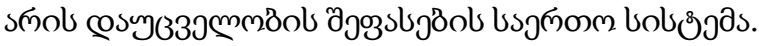




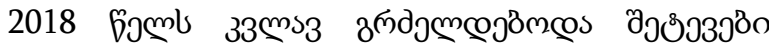

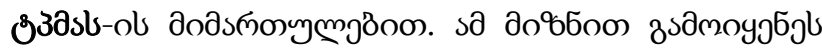

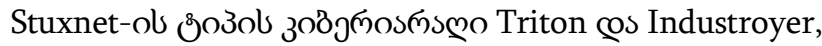

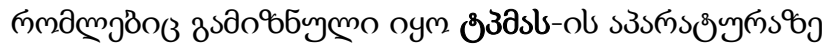

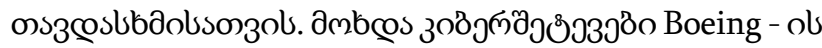
@os Taiwan Semiconductor Manufacturing Company - ob

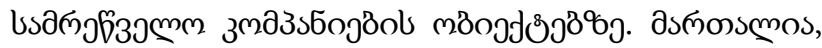

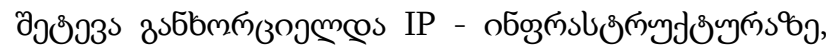

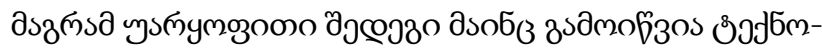

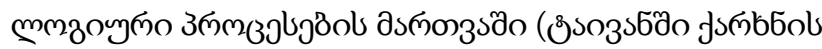

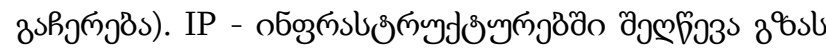

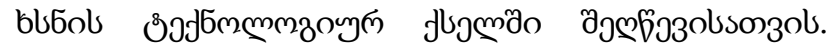

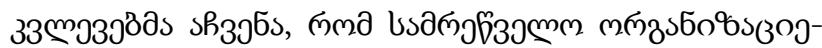

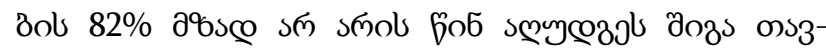

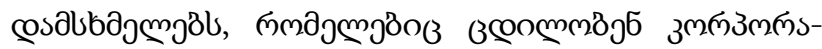

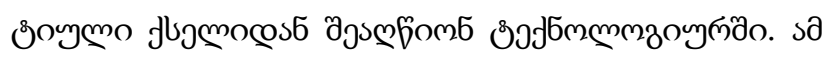

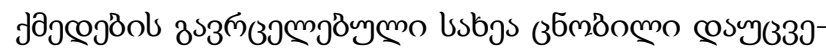

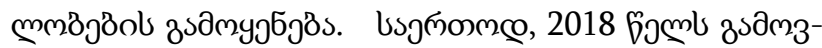

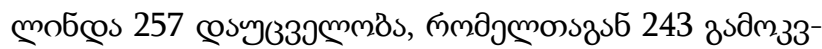

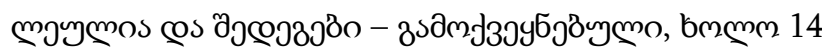

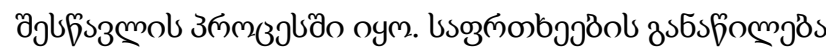

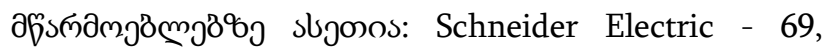
Siemens - 66, Advantech - 37, Moxa - 36 @os s.ə. amf-

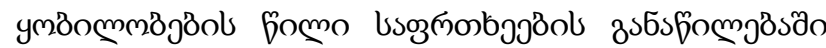

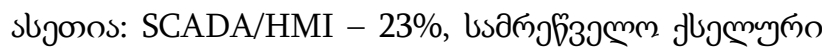

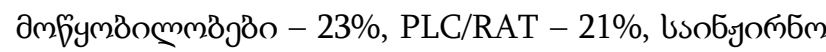

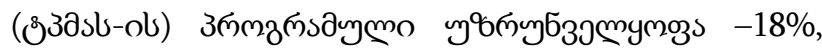

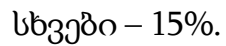

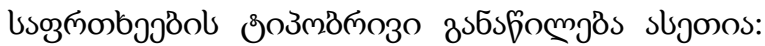

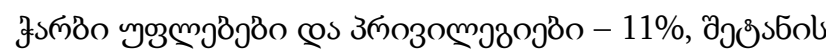

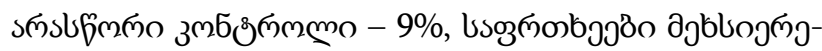

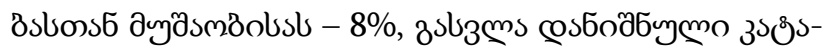

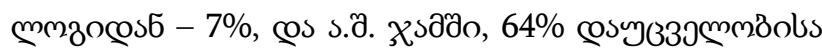

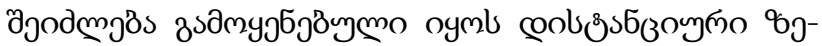

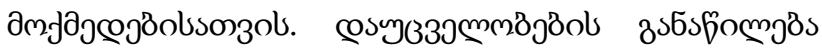

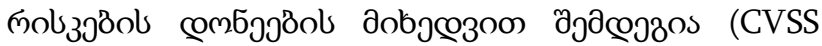

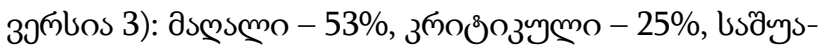

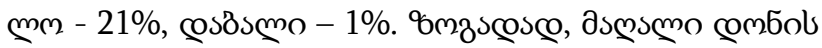

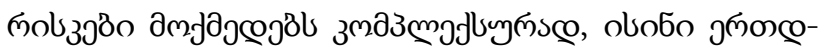

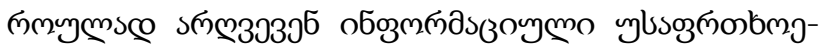

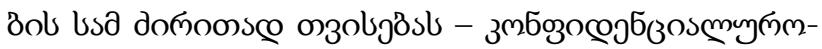

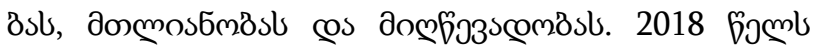

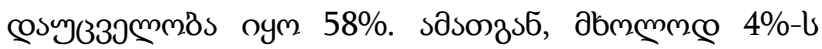

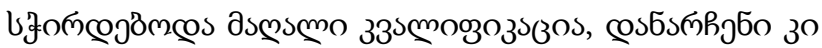

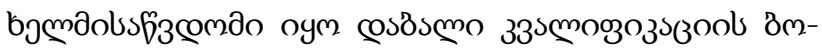

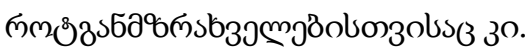

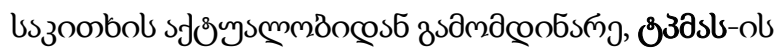

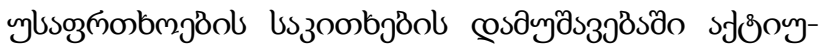

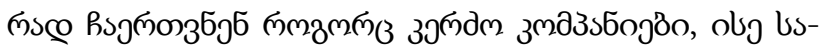

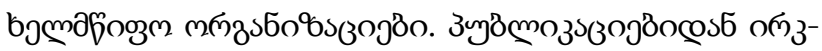

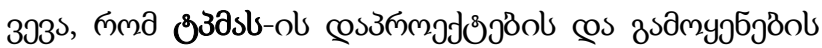

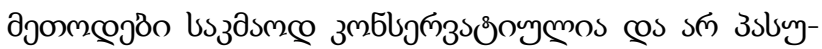

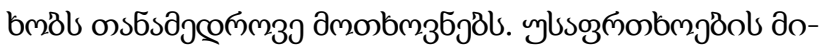

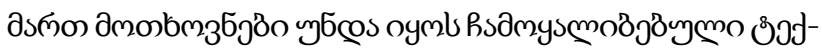

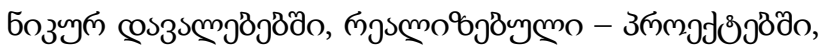

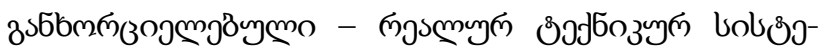

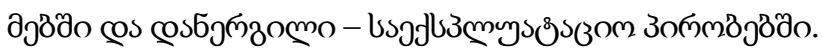

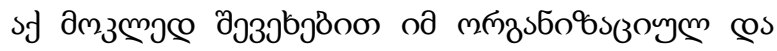

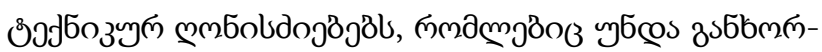

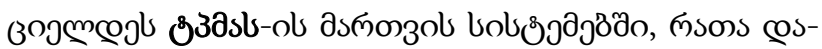

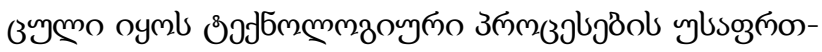

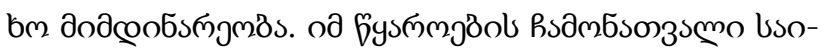

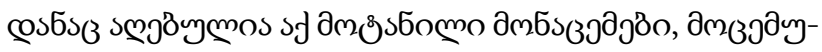

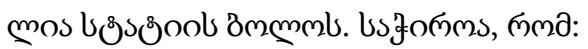

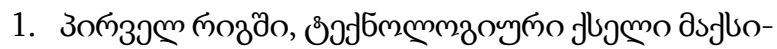

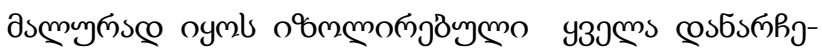




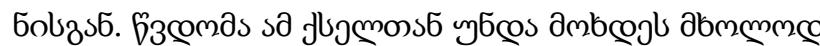

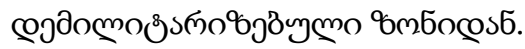

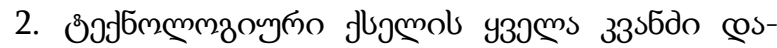

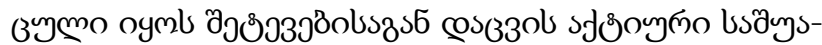

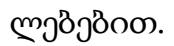

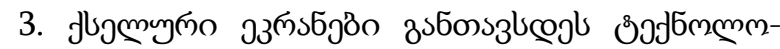

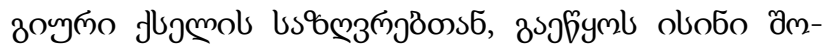

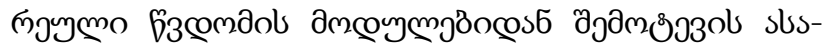

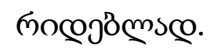

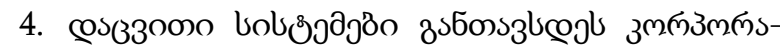

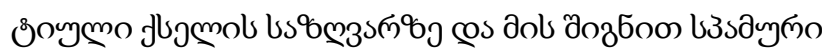

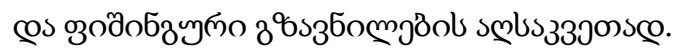

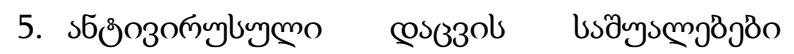

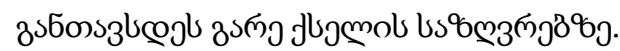

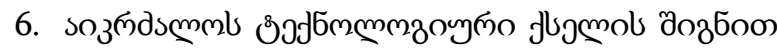

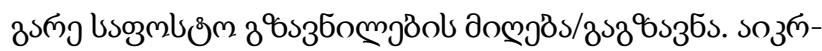

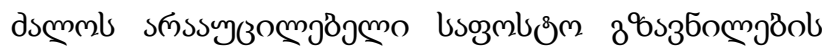

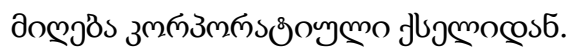

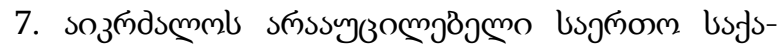

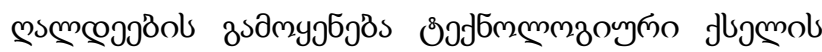
Әозбоо.

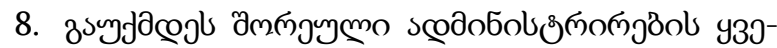

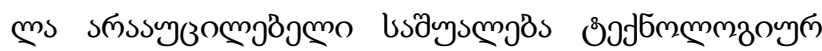
flomð̊o.

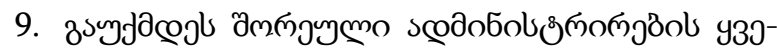

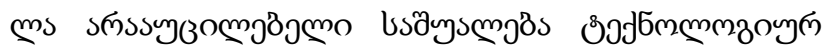

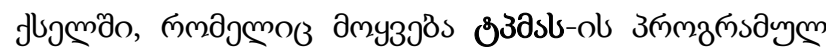

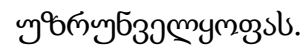

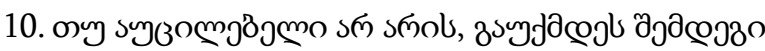

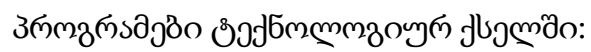

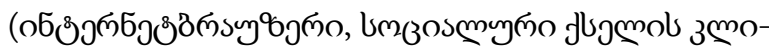

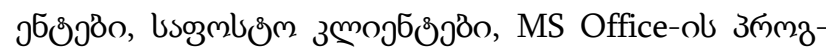

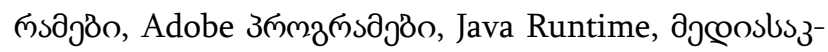

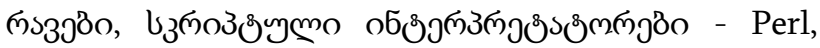
Python, PHP, ১๓ьмеов

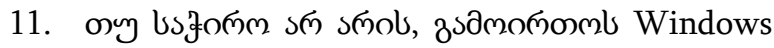
Script Host;

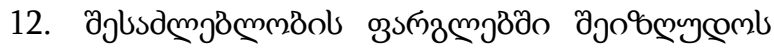
SeDebugPrivilege-ol zsдmyjбjos;

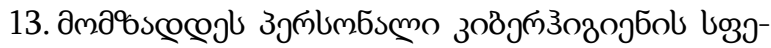
๓๓๐ð๐;

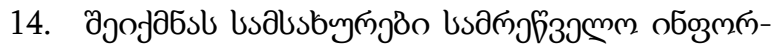

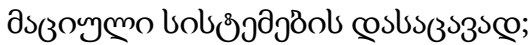

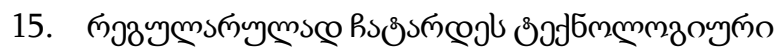

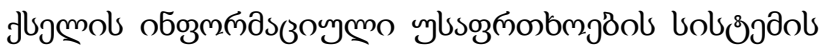

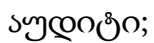

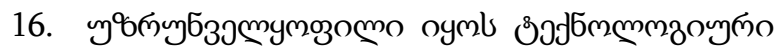

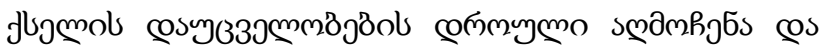
mozzocoszos;

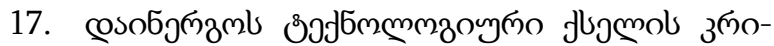

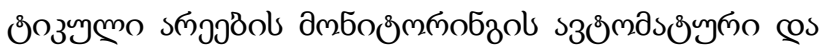

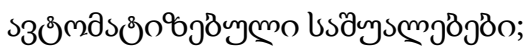

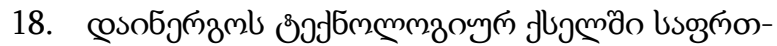
bajöol oб

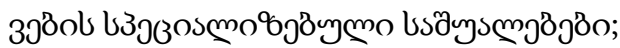

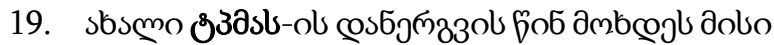

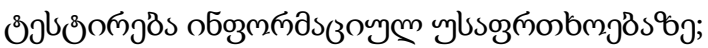

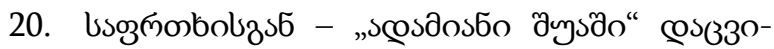

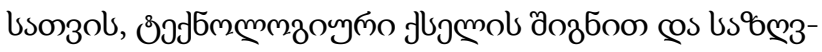

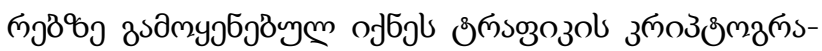

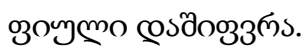

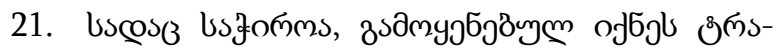

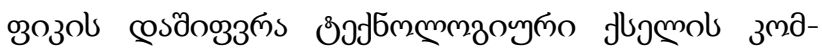

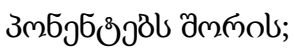

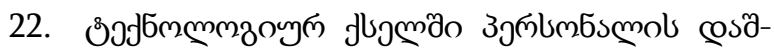

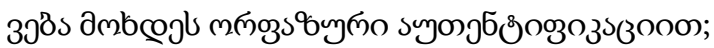




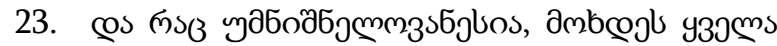

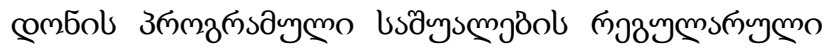
3stsbemgass.

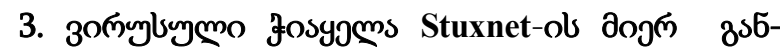

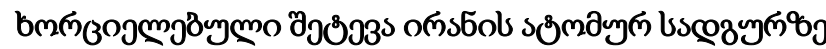

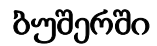

sasbfiobson, oms

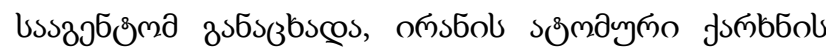

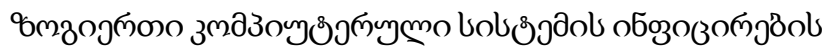

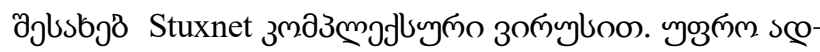

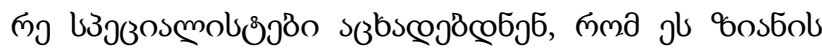

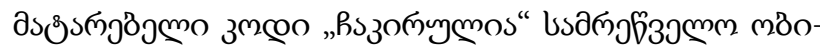

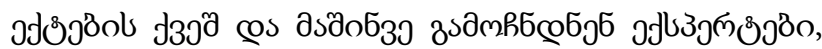

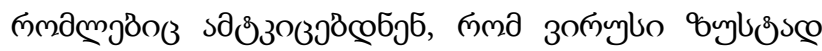

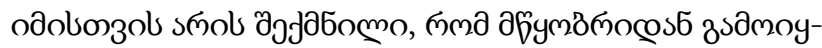

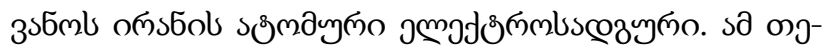

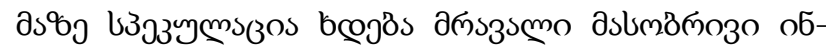

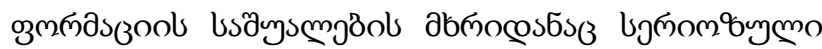

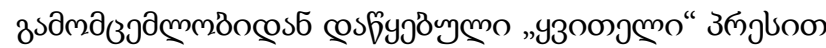

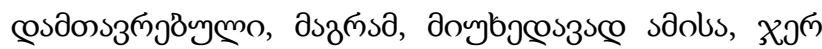

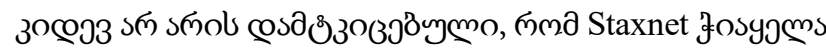

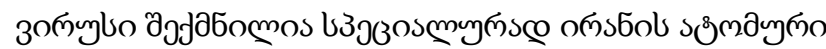

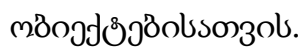

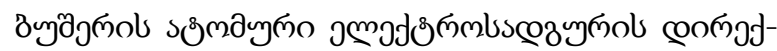

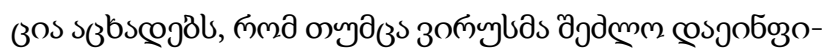

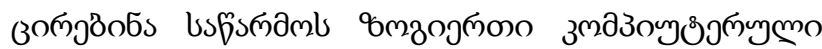

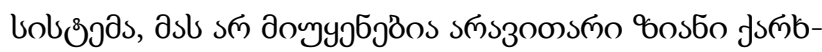

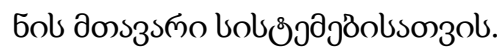

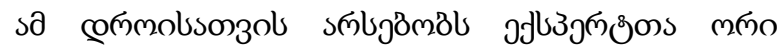

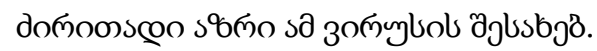

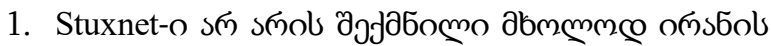

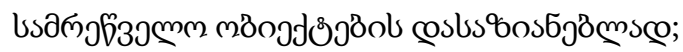

ISSN 1512-0996

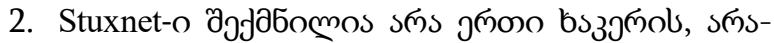

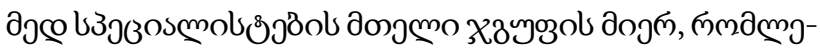

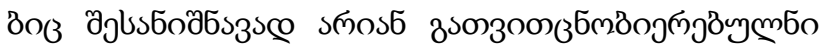

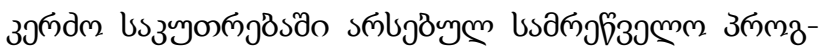

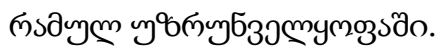

jl चзsбsьзб

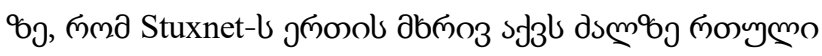

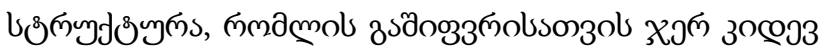

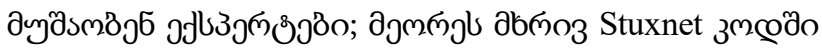

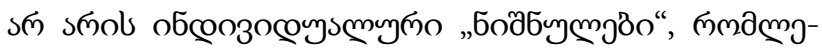

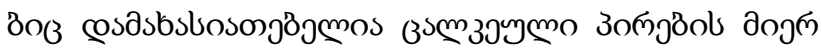

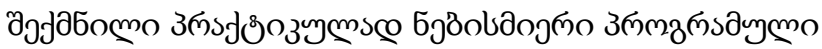

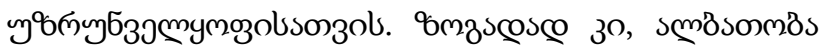

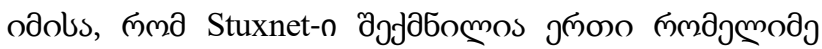

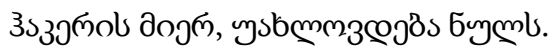

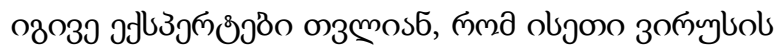

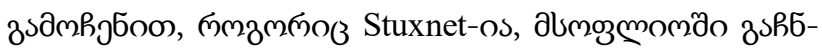

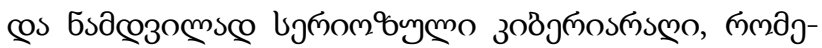

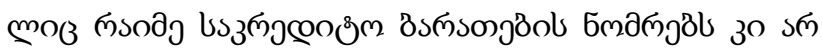

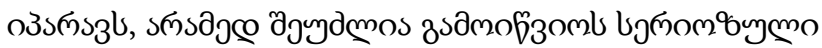

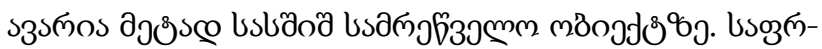

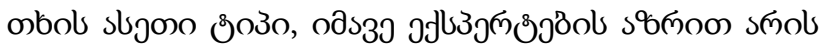

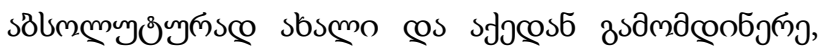

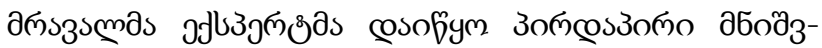

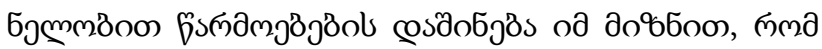

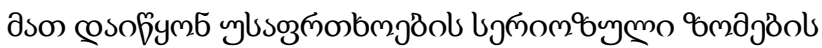
8.

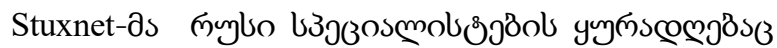

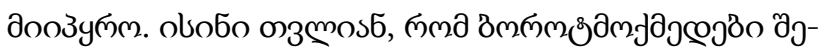

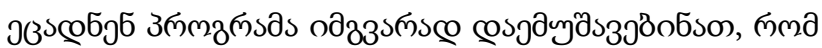

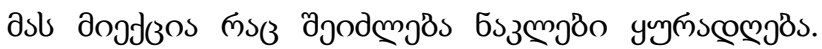

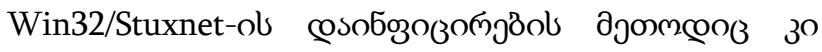

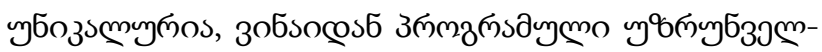




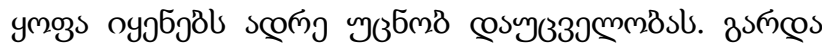

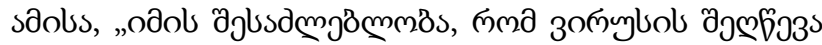

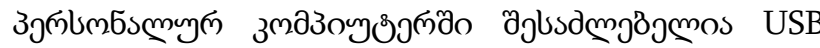

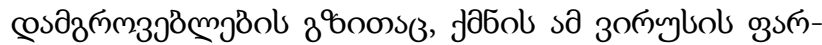

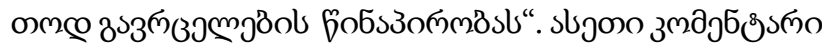

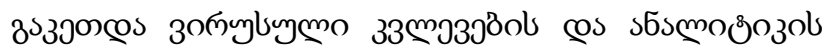

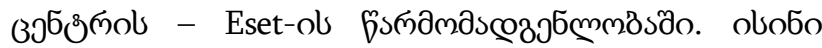

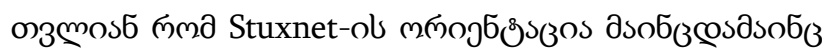

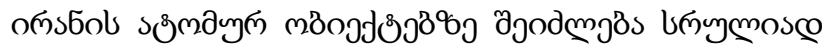

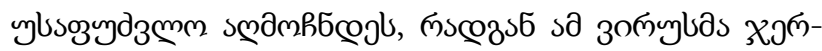

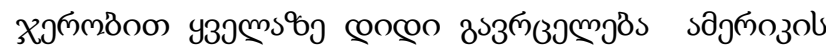

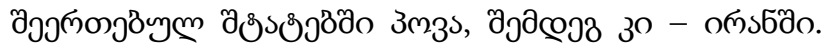

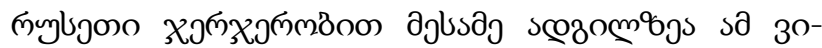

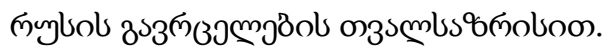

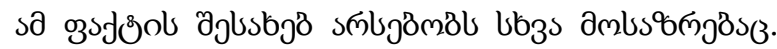

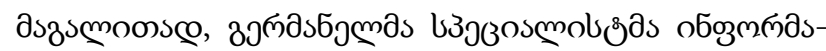

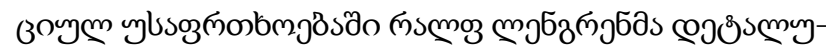

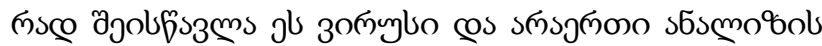

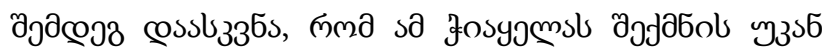

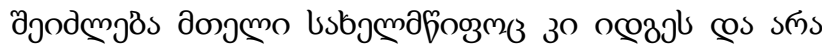

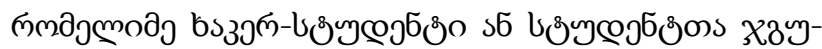

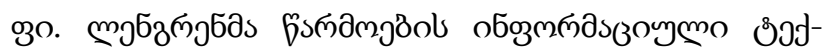

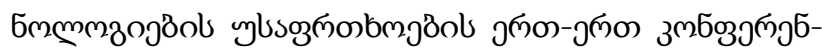

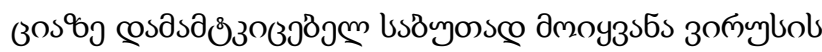

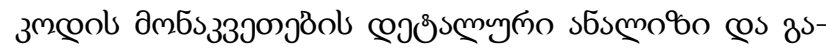

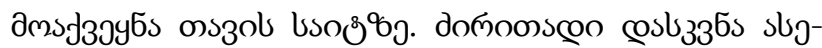

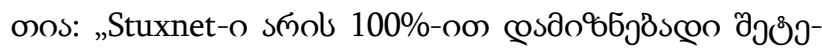

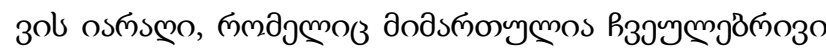

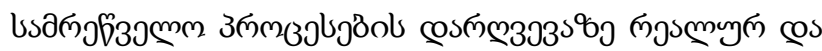

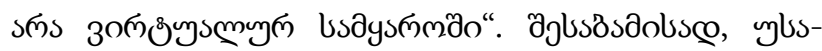

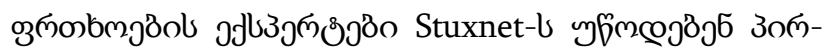

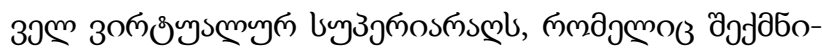

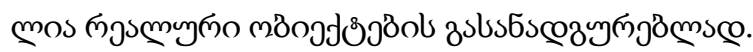

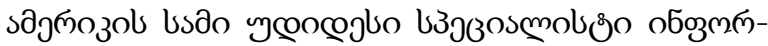

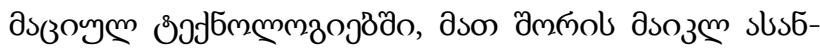

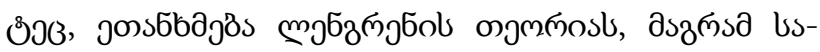

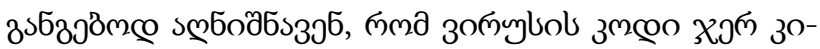

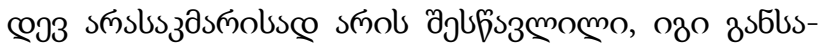

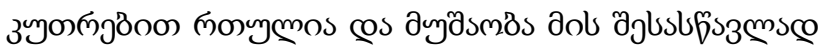

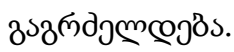

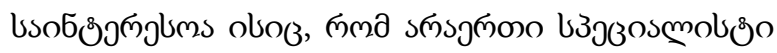

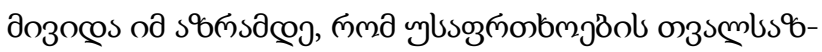
๓obnom oms

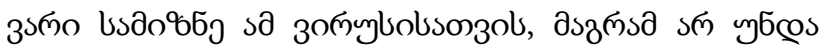

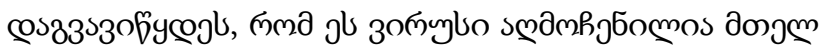

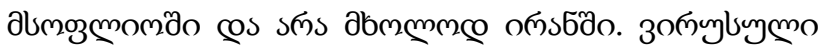

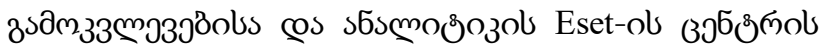

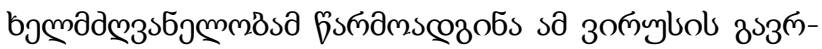

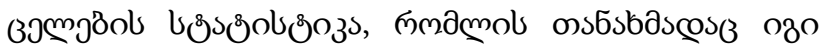

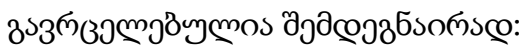

$$
\begin{aligned}
& \text { о๓ைs6ே - 52,2\% } \\
& \text { обсомбృรัos - 17,4\% } \\
& \text { обемуоло - 11,3\% }
\end{aligned}
$$

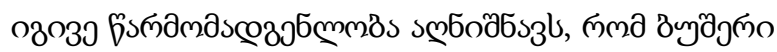

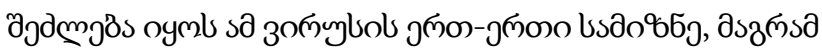

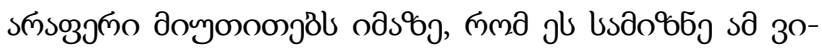

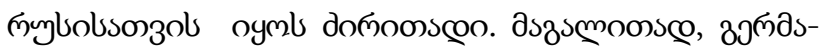

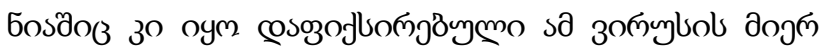

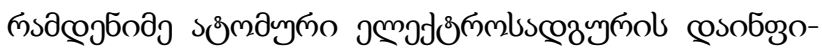

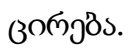

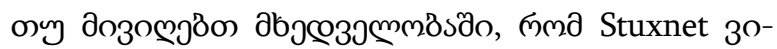

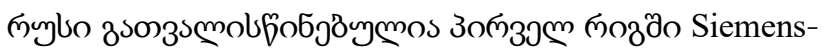

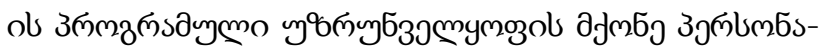

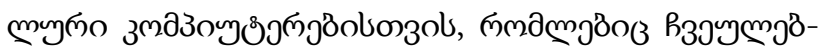

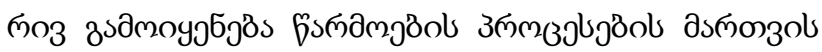




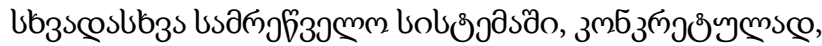

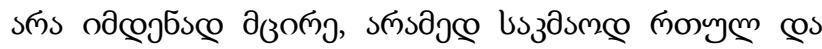

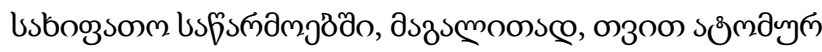

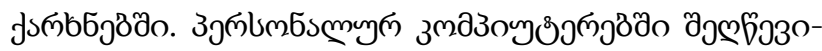
bsomzol Stuxnet-n oyjбjal os Widows-ob lsa cosy(339-

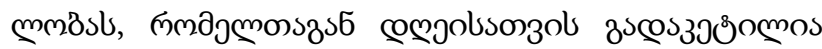

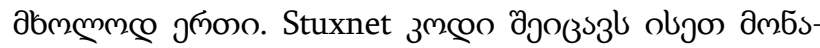

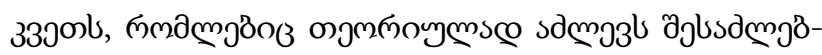

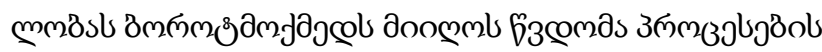

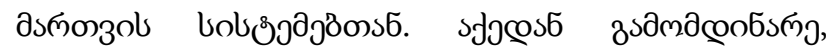

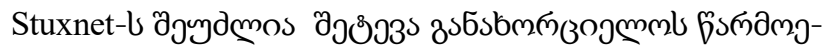

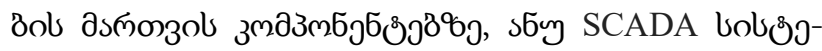

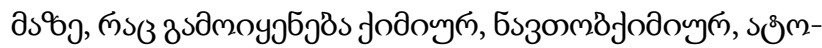

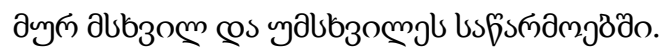

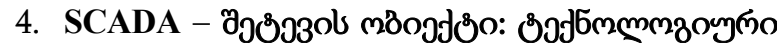

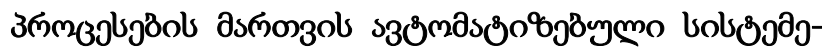

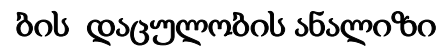

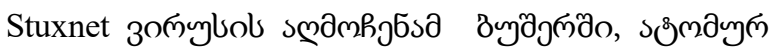

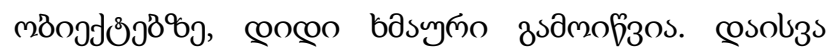

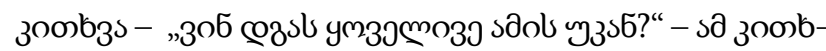

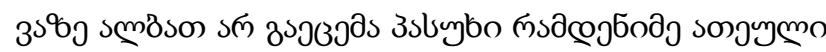

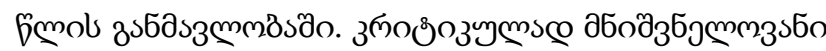

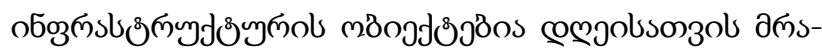

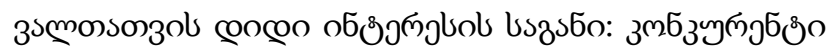

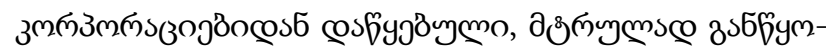

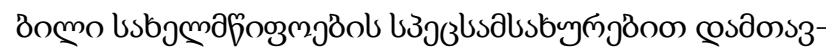

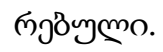

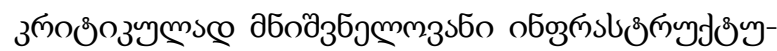

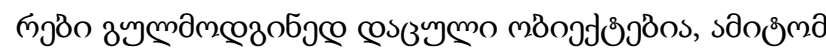

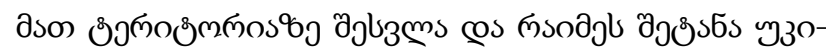

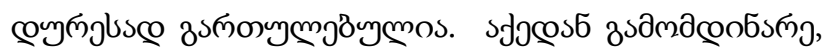

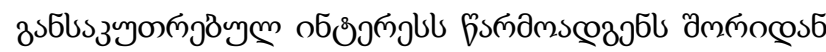

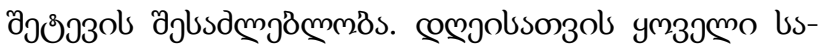

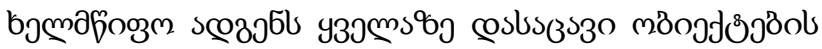

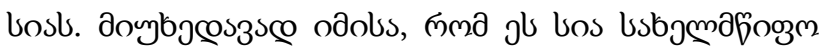

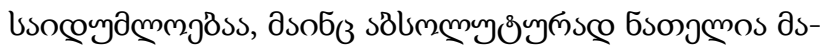

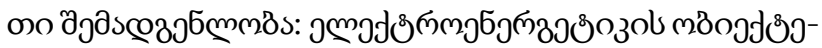

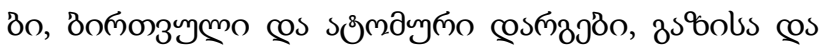

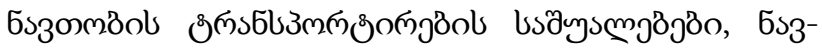

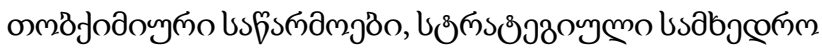

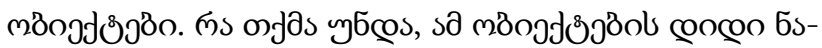

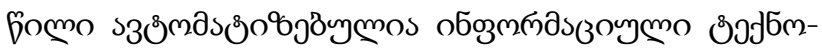

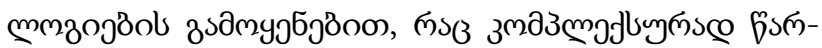

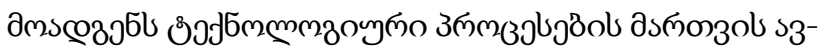

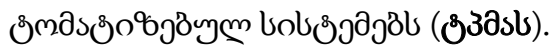

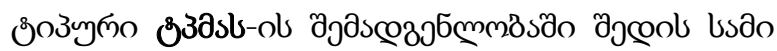

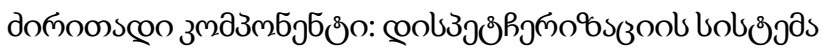

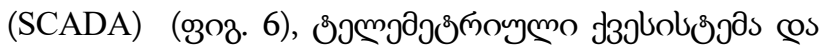

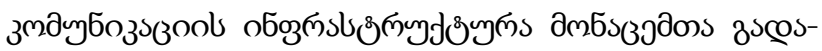

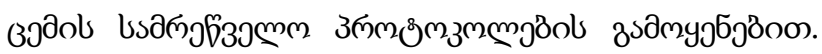

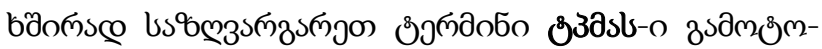

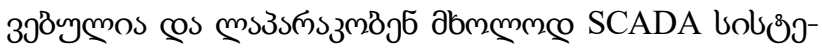

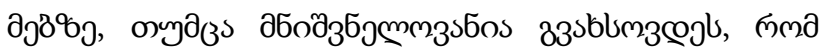

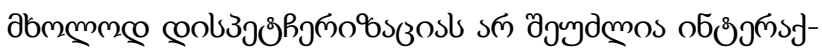

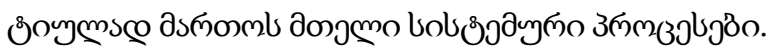

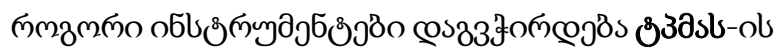

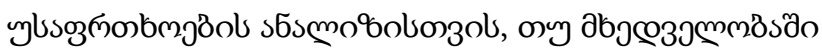

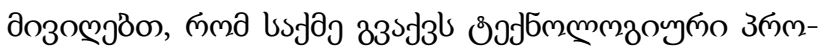

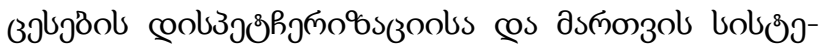

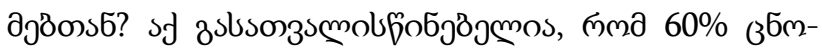

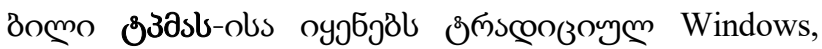

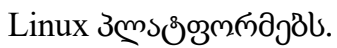

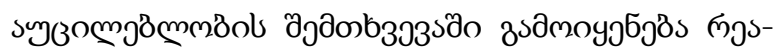

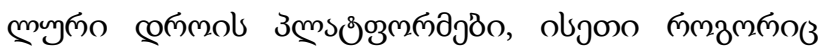

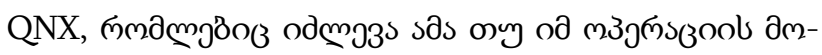




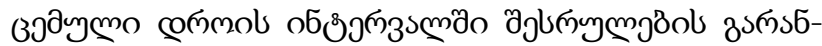

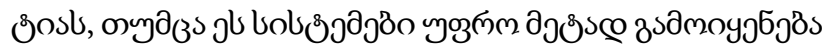

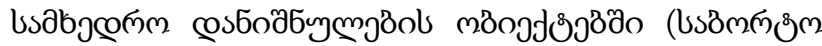

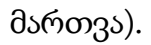

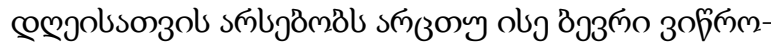

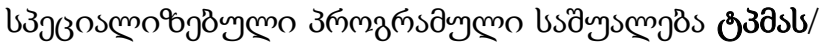

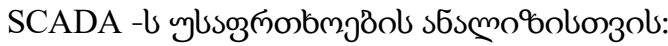

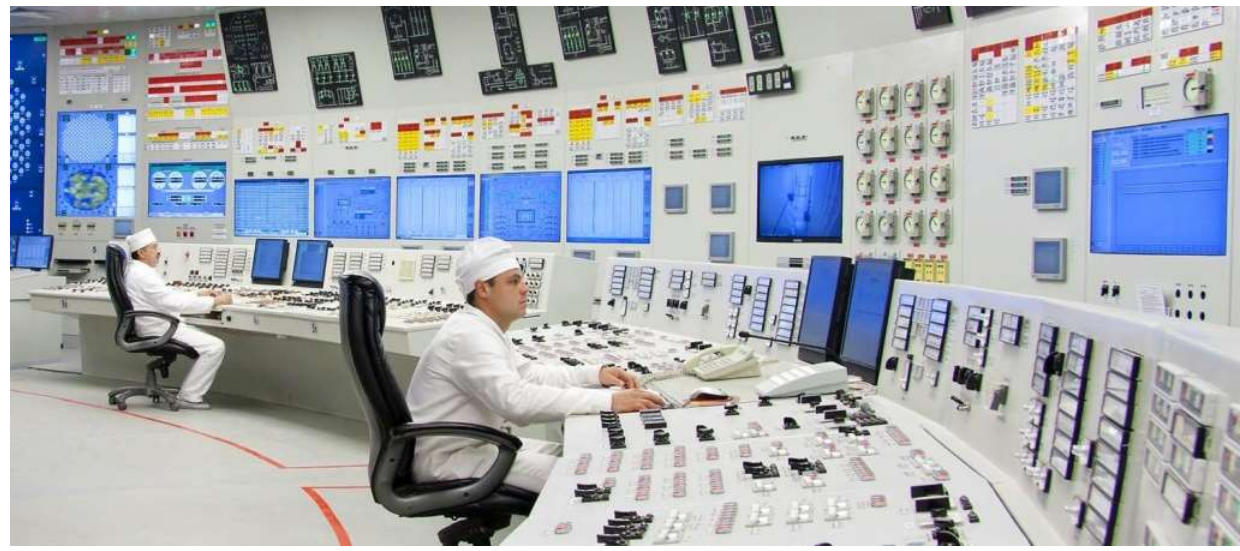

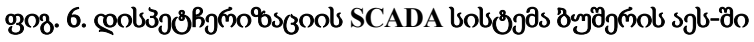

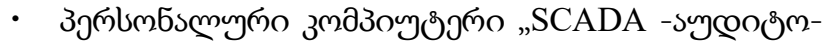

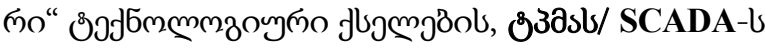

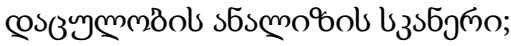

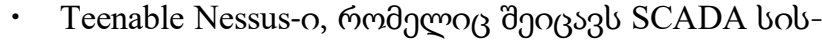

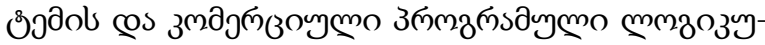

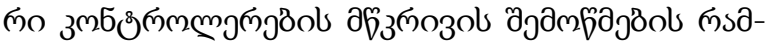

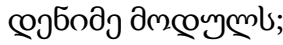

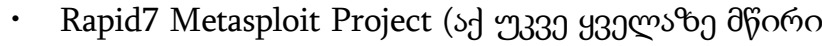

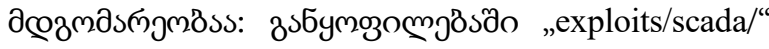

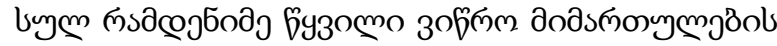
บலீంறுంலீSs).

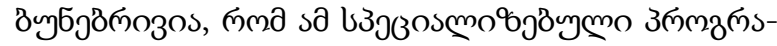

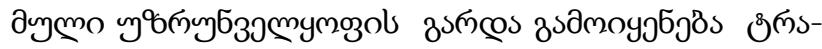

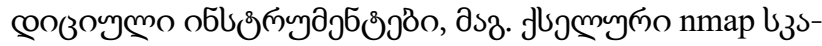

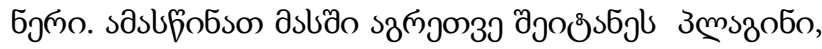

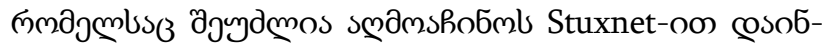

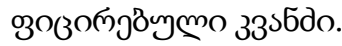

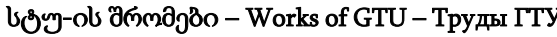
№4 (522), 2021

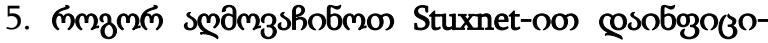

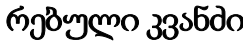

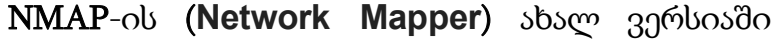

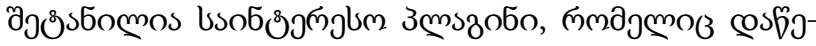

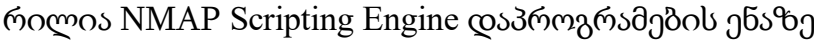
LUA. dobo bsbymos - „stuxnet-detect“.

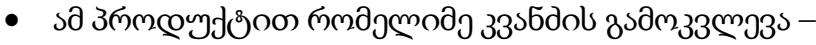

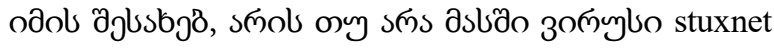

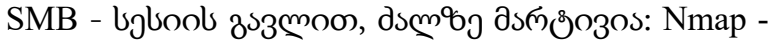
script stuxnet-detect - p $445<$ host $>$.

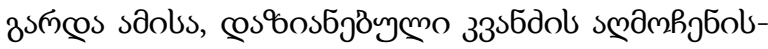

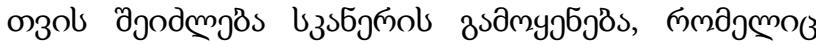

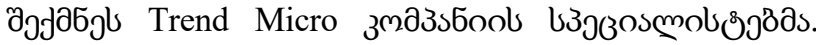

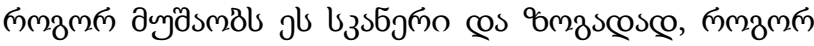

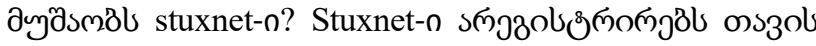

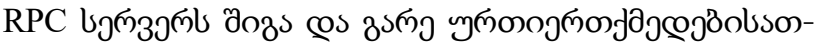

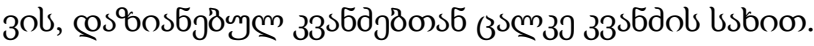

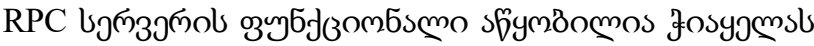




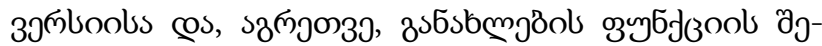

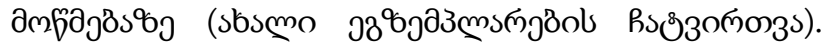

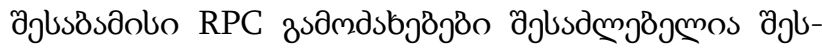

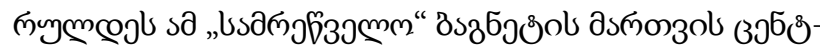

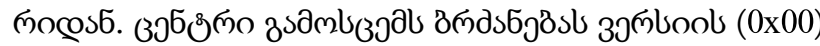

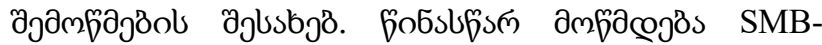

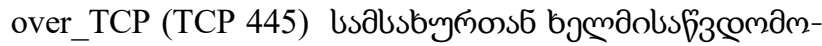

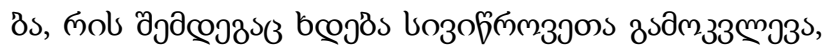

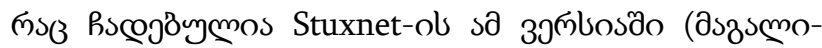

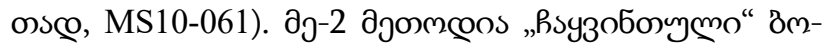

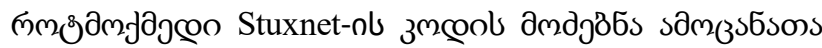

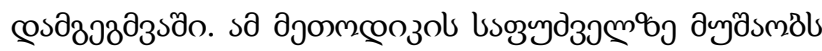
Trend Micro bзsбgตno.

\section{$\cos 333^{6 s}$}

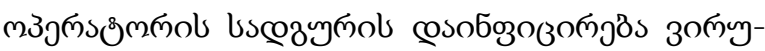

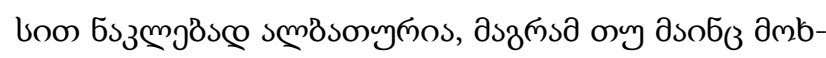

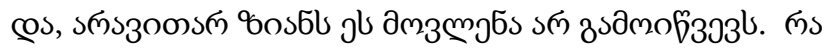

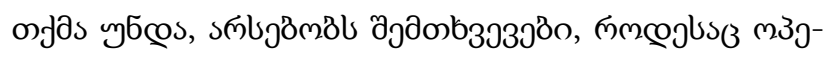

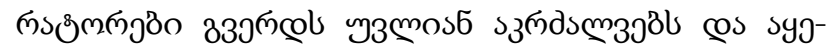

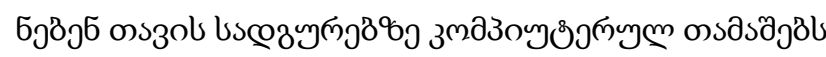

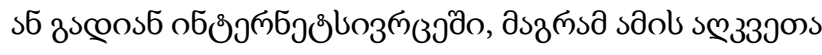

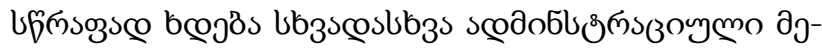

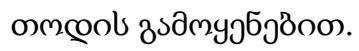

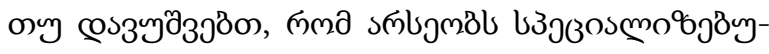

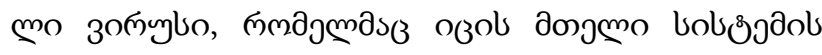

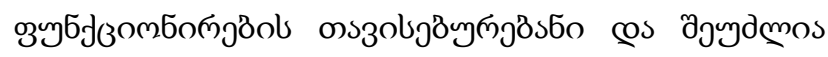

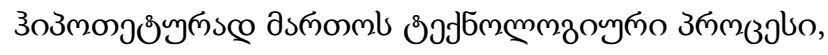

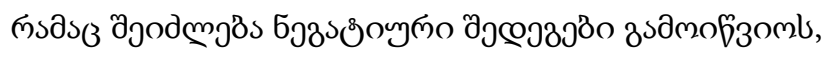

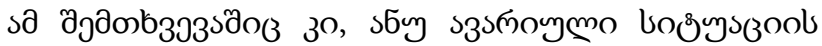

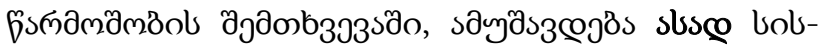

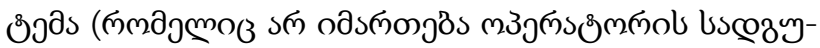

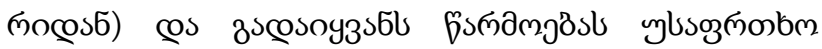

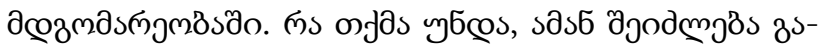

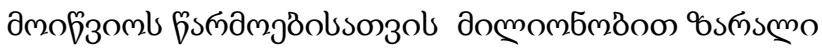

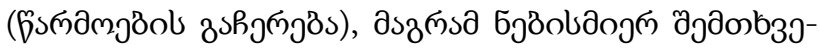

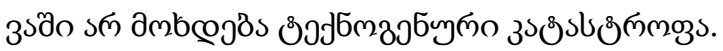

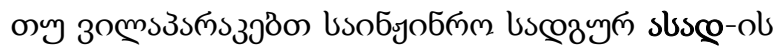

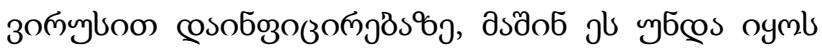

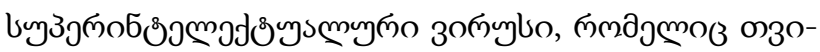

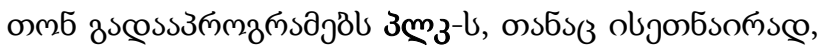

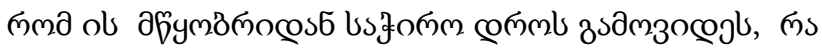

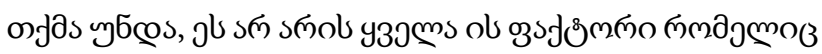

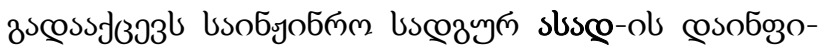

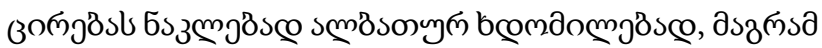

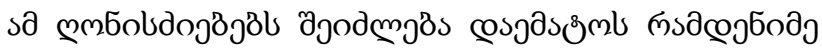

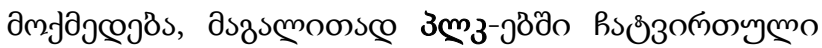

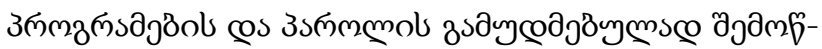

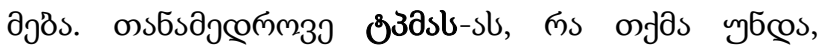

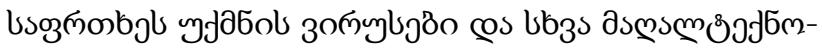

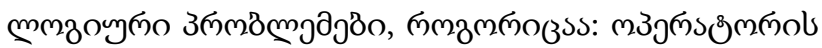

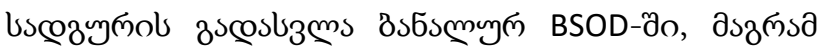

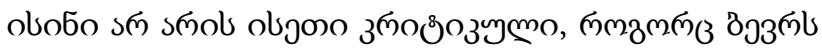

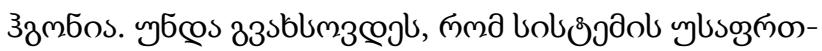

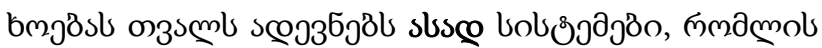

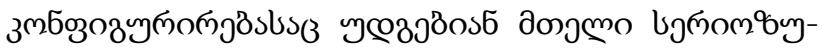
mmäooss cos bogुmonbomon.

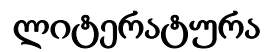

1. Journal Hacker. (2011, July 8). SCADA at Gunpoint: Security Analysis of an Automated Process Control System. Habr.Com. https://habr.com/ru/company/xakep/blog/123672/ 
2. Stuxnet таки добрался до иранского ядерного завода в Бушере/26 сентября 2010

3. Agadzhanov, M. (2010, September 26). Stuxnet Reached to Iranian Nuclear Plant in Bushehr. Habr.Com. https://habr.com/ru/post/104973/

4. Modern Automated Process Control System. (2010, October 4). Habr.Com. https://habr.com/ru/post/105375/ https://habr.com/ru/post/105375/

UDC 681.3.06

SCOPUS CODE 1802

https://doi.org/10.36073/1512-0996-2021-4-46-61

\title{
Analysis of the Security of Modern Automated Technological Processes Control Systems: Attack on a SCADA Object
}

\author{
Jemal Grigalashvili Department of Control Systems, Georgian Technical University, Georgia, 0160, Tbilisi, \\ 77 M. Kostava str. \\ E-mail: j.grigalishvili@gtu.ge \\ Zaur Jojua Department of Computer Engineering, Georgian Technical University, Georgia, 0160, \\ Tbilisi, 77 M. Kostava str. \\ E-mail: jojuazauri@yahoo.com \\ Nino Jojua Department of Computer Engineering, Georgian Technical University, Georgia, 0160, \\ Tbilisi, 77 M. Kostava str. \\ E-mail: jojua_nina@gmail.com
}

\section{Reviewers:}

K. Kotrikadze, Professor, Faculty of Informatics and Control Systems, GTU

E-mail: ketino27@gmail.com

K. Odisharia, Professor, Faculty of Informatics and Control Systems, GTU

E-mail: o_korneli@yahoo.com

\begin{abstract}
Modern automated technology process control systems and the chances of attacks on them are examined in this article. It studies worm virus, Stuxnet, and its detection at the Bushehr Nuclear Power Plant. It also analyzes ways of carrying out attacks on critically important objects, and provides analytical tools for the security of technological process systems. The ways for discovering nodes compromised by the Stuxnet virus are proposed. The article considers technological network of typical topology and its typical vulnerabilities; it analyzes the Modbus protocol, the routing system, and passwords on Cisco routers.
\end{abstract}

Keywords: Bushehr Nuclear Power Plant; Cisco router; Modbus protocol; passwords; routing system; SCADA; Stuxnet virus; the security of modern automated technology process control systems. 
UDC 681.3.06

SCOPUS CODE 1802

HTTPS://DOI.ORG/10.36073/1512-0996-2021-4-46-61

\title{
Анализ безопасности современных автоматизированных систем управления технологическими процессами: атака на объект SCADA
}

\author{
Джемал Департамент систем управления, Грузинский технический университет, Грузия, \\ Григалашвили 0160, Тбилиси, ул. М. Костава 77 \\ E-mail: j.grigalishvili@gtu.ge \\ Заур Джоджуа Департамент компьютерной инженерии, Грузинский технический университет, \\ Грузия, 0160, Тбилиси, ул. М. Костава 77 \\ E-mail: jojuazauri@yahoo.com \\ Нино Джоджуа Департамент компьютерной инженерии, Грузинский технический университет, \\ Грузия, 0160, Тбилиси, ул. М. Костава 77 \\ E-mail: jojua_nina@gmail.com
}

\section{Рецензенты:}

К. Котрикадзе, профессор факультета информатики и систем управления ГТУ

E-mail: ketino27@gmail.com

К. Одишария, профессор факультета информатики и систем управления ГТУ

E-mail: o_korneli@yahoo.com

Аннотация. (.....) В статье рассматриваются современные автоматизированные технологические системы управления процессом и вероятность кибератак на них. Изучается вирус Stuxnet и его обнаружение на Бушерской атомной электростанции. Также анализируются способы совершения нападений на критически важные объекты и предоставляются аналитические инструменты для обеспечения безопасности систем технологических процессов. Предложены способы обнаружения узлов, скомпрометированных вирусом Stuxnet. Более того, в статье рассматривается технологическая сеть типичной топологии и ее типичные уязвимости; анализируется протокол Modbus, система маршрутизации и пароли на маршрутизаторах Сisco.

Ключевые слова: АЕС «Бушер»; безопасность современных автоматизированных систем управления технологическими процессами; вирус Stuxnet; маршрутизатор Cisco; протокол Modbus; пароли; система маршрутизации; SCADA.

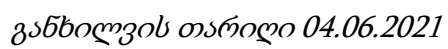

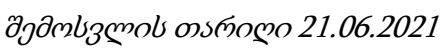

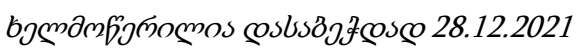

